\title{
Association between Tetrodotoxin Resistant Channels and Lipid Rafts Regulates Sensory Neuron Excitability
}

\author{
Alessandro Pristerà ${ }^{1}$, Mark D. Baker ${ }^{2}$, Kenji Okuse ${ }^{1 *}$ \\ 1 Division of Cell and Molecular Biology, Faculty of Natural Sciences, Imperial College London, London, United Kingdom, 2 Neuroscience and Trauma Centre, Blizard
} Institute, Queen Mary University of London, Barts and The London School of Medicine and Dentistry, London, United Kingdom

\begin{abstract}
Voltage-gated sodium channels (VGSCs) play a key role in the initiation and propagation of action potentials in neurons. $\mathrm{Na}_{\mathrm{V}} 1.8$ is a tetrodotoxin (TTX) resistant VGSC expressed in nociceptors, peripheral small-diameter neurons able to detect noxious stimuli. Nav1.8 underlies the vast majority of sodium currents during action potentials. Many studies have highlighted a key role for $\mathrm{Nav}_{\mathrm{v}} 1.8$ in inflammatory and chronic pain models. Lipid rafts are microdomains of the plasma membrane highly enriched in cholesterol and sphingolipids. Lipid rafts tune the spatial and temporal organisation of proteins and lipids on the plasma membrane. They are thought to act as platforms on the membrane where proteins and lipids can be trafficked, compartmentalised and functionally clustered. In the present study we investigated $\mathrm{Na}_{\mathrm{V}} 1.8 \mathrm{sub}-$ cellular localisation and explored the idea that it is associated with lipid rafts in nociceptors. We found that $\mathrm{Na}_{\mathrm{V}} 1.8$ is distributed in clusters along the axons of DRG neurons in vitro and ex vivo. We also demonstrated, by biochemical and imaging studies, that $\mathrm{Na}_{\mathrm{v}} 1.8$ is associated with lipid rafts along the sciatic nerve ex vivo and in DRG neurons in vitro. Moreover, treatments with methyl- $\beta$-cyclodextrin $(M \beta C D)$ and 7-ketocholesterol $(7 K C)$ led to the dissociation between rafts and $\mathrm{Na}_{\mathrm{v}}$ 1.8. By calcium imaging we demonstrated that the lack of association between rafts and $\mathrm{Na}_{\mathrm{v}} 1.8$ correlated with impaired neuronal excitability, highlighted by a reduction in the number of neurons able to conduct mechanically- and chemically-evoked depolarisations. These findings reveal the sub-cellular localisation of $\mathrm{Na}_{\mathrm{v}} 1.8$ in nociceptors and highlight the importance of the association between $\mathrm{Na}_{v} 1.8$ and lipid rafts in the control of nociceptor excitability.
\end{abstract}

Citation: Pristerà A, Baker MD, Okuse K (2012) Association between Tetrodotoxin Resistant Channels and Lipid Rafts Regulates Sensory Neuron Excitability. PLoS ONE 7(8): e40079. doi:10.1371/journal.pone.0040079

Editor: J. David Spafford, University of Waterloo, Canada

Received February 8, 2012; Accepted June 5, 2012; Published August 1, 2012

Copyright: (c) 2012 Pristerà et al. This is an open-access article distributed under the terms of the Creative Commons Attribution License, which permits unrestricted use, distribution, and reproduction in any medium, provided the original author and source are credited.

Funding: This work was supported by the Wellcome Trust UK (080958/Z/06/Z and 083259/C/07/Z), and AP and KO are members of London Pain Consortium. The funders had no role in study design, data collection and analysis, decision to publish, or preparation of the manuscript.

Competing Interests: The authors have declared that no competing interests exist.

*E-mail: k.okuse@imperial.ac.uk

\section{Introduction}

Voltage-gated sodium channels (VGSCs) are necessary for the generation and propagation of action potentials [1]. Three of the VGSGs isoforms encoded in mammals are TTX resistant (TTXr): $\mathrm{Na}_{V} 1.5$ (expressed in the cardiac tissue [2], $\mathrm{Na}_{V} 1.8$ and $\mathrm{Na}_{\mathrm{V}} 1.9$, both expressed in nociceptors. More specifically, $\mathrm{Na}_{\mathrm{V}} 1.8$ is expressed in unmyelinated, C-type, small-diameter sensory neurons [3]. These cells are responsible for the detection of noxious stimuli and play a major role in the hyperalgesia and allodynia that accompany chronic pain states [4]. Electrophysiological studies in C-fibre cell bodies have demonstrated that $\mathrm{Na}_{\mathrm{V}} 1.8$ is essential for normal electrogenesis, underlying the vast majority $(>85 \%)$ of the inward current that ows during the upstroke of action potentials [5]. On the other hand $\mathrm{Na}_{\mathrm{V}} 1.9$ does not contribute to action potentials but is involved in setting the resting membrane potential [6].

Given the key electrophysiological features of $\mathrm{Na}_{\mathrm{V}} 1.8$ and its restricted expression, pharmacological and genetic studies on knock-out mice have been carried out to investigate its role in inflammatory and chronic pain states. Indeed it has been found that $\mathrm{Na}_{\mathrm{V}} 1.8$ play a key role in both inflammatory and neuropathic pain conditions $[7,8,9]$.

Unlike the case of myelinated fibres, which show restricted localisation of VGSCs at nodes of Ranvier and axon initial segments, the precise localisation of VGSGs in unmyelinated fibres has not been investigated in detail, and the sub-cellular localisation of $\mathrm{Na}_{\mathrm{V}} 1.8$ still remain uncharacterised. It is believed that VGSCs are uniformly distributed in unmyelinated fibres, based on indirect evidences such as continuous conduction and homogeneous appearance of freeze fracture photomicrographs [10]. Some reports suggest that $\mathrm{Na}_{\mathrm{V}} 1.8$ is found along the entire length of the unmyelinated sensory axons in the cornea [11] and the sciatic nerve [12], although the same group has shown that $\mathrm{Na}_{\mathrm{V}} 1.8$ appeared to be in clusters at the varicosities and inter-connecting regions of the nerve terminals in unmyelinated axons of intraepidermal fibres [13].

Lipid rafts are defined as "dynamic, nanoscale, sterolsphingolipids enriched, ordered assemblies of proteins and lipids" $[14,15,16]$. Compared to the liquid disordered state of the bulk membrane they exist in a liquid ordered state and they are resistant to non-ionic detergent lysis at $4^{\circ} \mathrm{C}[17,18]$. The core role of lipid rafts is to laterally organise the cell membrane, both spatially and temporally. They act as hubs on the cellular membrane where proteins can be sorted and functionally localised. Lipid rafts regulate the trafficking, clustering and electrophysiological properties of ion channels. Overall, they contribute to shape cell membrane excitability (Reviewed in [19]). For example, hippocampal neurons contain lipid rafts in the dendrites, and rafts are important for the stabilisation of AMPA receptor clusters [20]. 
Potassium channel $\mathrm{K}_{\mathrm{V}} 2.1$ is also associated with lipid rafts, and rafts directly modulate its electrophysiological features [21].

Several studies have directly investigated the membrane trafficking of $\mathrm{Na}_{\mathrm{V}} 1.8$ (reviewed in [22]. However, in this study we focussed on $\mathrm{Na}_{\mathrm{V}} 1.8$ localisation and association with lipid rafts in DRG neurons. We found that $\mathrm{Na}_{\mathrm{V}} 1.8$ is normally localised in clusters along the axons of unmyelinated neurons and that it associates with lipid rafts. Importantly, the disruption of lipid rafts in DRG neurons led to the shift of $\mathrm{Na}_{\mathrm{V}} 1.8$ into the non-raft portion of the membrane and this redistribution correlated with impaired neuronal excitability.

\section{Materials and Methods}

\section{Cell culture}

DRGs from female Wistar rats (150 grams) were harvested in cold DMEM and any excess dorsal roots and spinal nerves were trimmed under a stereo microscope. DRGs were incubated with $0.125 \%$ Collagenase XI (Sigma) and $0.1 \mathrm{mg} / \mathrm{ml}$ DNase II (Sigma) in DMEM for $90 \mathrm{~min}$ at $37^{\circ} \mathrm{C}$. After enzymatic digestion, DRGs were triturated with a cut $1 \mathrm{ml}$ tip until a cell suspension was obtained. Cells were spun down, resuspended in pre-warmed DMEM and filtered through a $70 \mu \mathrm{m}$ mesh (BD Biosciences). DRG neurons were recovered by using 10\% BSA (PAA)/ DMEM cushions and plated on $13 \mathrm{~mm}$ glass coverslips coated with poly-Llysine and laminin in complete media (DMEM, 10\% fetal bovine serum (FBS), penicillin/streptomycin (1:100; Sigma), NGF (50 ng/ $\mathrm{ml}$; Peprotech) and aphidicolin (10 $\mathrm{M}$; Sigma). 10,000 and 150,000 cells per coverslips were plated for immunofluorescence and biochemistry purposes, respectively. Cells were maintained in a $95 \%$ air $/ 5 \% \mathrm{CO}_{2}$ humidified incubator.

\section{Immunofluorescence and GM1 detection on cultured DRG neurons}

DRG neurons were washed in PBS (Gibco; Invitrogen) and fixed with $4 \%$ paraformaldehyde (PFA) for $10 \mathrm{~min}$ at room temperature (RT). Following washes in PBS, DRG neurons were incubated with primary antibodies. All the antibodies were diluted in $10 \%$ goat serum (GS) for 1 hour at RT at the following dilution: rabbit anti $\mathrm{Na}_{\mathrm{V}} 1.8[23,24]$ 1:200, mouse anti-Peripherin (Chemicon) 1:200, mouse anti-NF200 (Chemicon) 1:500. After washes cells were incubated with fluorescently labeled secondary antibodies, diluted in 10\% GS for 1 hour at RT. When nuclear counterstain was needed, cells were incubated with Hoechst 33342 (Invitrogen) diluted 1:10000 in PBS for $10 \mathrm{~min}$ at RT and subsequently washed in PBS. Coverslips were mounted on glass slides with anti fade agent AF1 (Citifluor LTD) and sealed with nail varnish.

To detect GM1 ganglioside DRG neurons were washed with PBS and incubated with $1 \mu \mathrm{g} / \mathrm{ml}$ biotinylated cholera toxin $\beta$ subunit (CTB; Invitrogen) in PBS for $20 \mathrm{~min}$ at RT. After washes with PBS, DRG neurons were incubated with 1:1000 streptavidin-488 (Invitrogen) for $20 \mathrm{~min}$ at RT. Cells were washed in PBS, fixed with 4\% PFA (Sigma) for $10 \mathrm{~min}$ at RT. and processed for immunofluorescence.

Samples were analysed on a wide-field Nikon 80i microscope and pictures acquired with an ultrahigh-quality Nikon DXM1200F digital camera controlled with LUCIA G software.

\section{Electroporation of DRG neurons}

Exogenous DNA was delivered into DRG neurons by electroporation with a Neon transfection system (Invitrogen). Electroporation was carried out before plating the cells. The cell suspension was washed in PBS and spun down. The pellet was resuspended in $27 \mu$ l buffer $\mathrm{R}$ (Invitrogen) plus $3 \mu \mathrm{l}$ of plasmid DNA (concentration of plasmid DNA higher than $1 \mu \mathrm{g} / \mu \mathrm{l}$ ). The cell suspension was aspirated in a $10 \mu \mathrm{l}$ tip and the electric pulses delivered ( 2 pulses, 1200 volts, $20 \mathrm{msec}$ ). For electroporation purposes, 200,000 cells were electroporated in four rounds of electroporation. After the electric pulses neurons were plated in pre-warmed DMEM with $10 \%$ FBS without antibiotics. Two hours after plating, NGF was added to the cells. The day after plating, media was replaced with complete DMEM and media changed every two days.

\section{Teased fibre preparation from sciatic nerve and immunofluorescence}

Sciatic nerves were harvested and placed on top of a $2 \%$ gelatin (Sigma) coated glass coverslip. Under a stereomicroscope nerve fascicles were freed from the epineurium by pulling them with fine tips tweezers. The fascicles were dissociated in fibre bundles and single fibres by gently pulling them with forceps. The sciatic nerve fibres were washed in PBS and fixed in 4\% PFA. After washes fibres were permeabilised with $0.1 \%$ Triton X-100 in PBS 10 min at RT. Following washes, samples were blocked in 10\% GS in PBS for $30 \mathrm{~min}$ at RT and incubated with primary antibodies diluted in 10\% GS/PBS for 2 hours at RT. (rabbit anti Nav1.8 1:100, mouse anti Peripherin 1:100). After washes with PBS samples were incubated with fluorescently labelled secondary antibodies diluted in $10 \%$ GS in PBS for 1 hour at RT.

\section{Lipid raft purification}

35 DRGs and sciatic nerves (left and right; $70 \mathrm{mg}$ ) were dissected from female Wistar rats (150 grams) and homogenised, by using a glass pestle and mortar, in homogenisation buffer (150 mM NaCl, 5 mM dithiothreitol, 5 mM EDTA, 25 mM Tris$\mathrm{HCl}$, supplemented with 1:1000 protease inhibitor cocktail set III (Merck), pH 7.4). The homogenate was centrifuged at $3600 \mathrm{rpm}$ for $10 \mathrm{~min}$ at $4^{\circ} \mathrm{C}$ to pellet chromatin, the supernatant recovered and adjusted with Triton X-100 (Sigma) to give a final concentration of $1 \%$ Triton X-100. When DRG cultures were used, neurons were recovered by scraping the cells in homogenisation buffer supplemented with $1 \%$ Triton X-100.

Lipid rafts were purified by incubating the samples for $30 \mathrm{~min}$ on ice. The lysate was mixed with $60 \%$ OptiPrep (iodixanol; Sigma) to obtain a final concentration $40 \%$ OptiPrep. The $40 \%$ fraction was layered in a $5 / 16 \times 13 / 8$ inch ultracentrifuge tube (Beckman) with $30 \%$ and $0 \%$ OptiPrep layers prepared in homogenisation buffer with $1 \%$ Triton X-100.

Samples were finally centrifuged at $36000 \mathrm{rpm}$ for 4.5 hours and after centrifugation the whole gradient was recovered from the tubes. All procedures were carried out at $4{ }^{\circ} \mathrm{C}$, with pre-cooled solutions.

\section{Immunoblotting}

Equal volumes of the fractions recovered from ultracentrifugation were subjected to SDS-PAGE. After electrophoresis proteins were transferred onto PVDF membrane (Amersham) and non specific sites were blocked with 5\% dried fat-free milk dissolved in PBS supplemented with $0.1 \%$ Tween-20 (Sigma) (PBS-T) overnight $(\mathrm{ON})$ at $4^{\circ} \mathrm{C}$.

After washes in PBS-T membranes were incubated with the following primary antibodies: rabbit anti $\mathrm{Na}_{\mathrm{V}} 1.8$ [23,24], mouse anti Flotillin-1 (DB Biosciences), mouse anti transferrin receptor (Zymed; Invitrogen). All antibodies were used 1:1000 for 1 hour at RT. Following washes the membranes were incubated with the 
appropriate secondary antibodies conjugated to horseradish peroxidase (HRP) diluted in $10 \%$ GS in PBS-T.

For dot blot analysis, $1 \mu \mathrm{l}$ of each layer recovered from the centrifugation step was applied to a nitrocellulose membrane $(0.45 \mu \mathrm{m}$; Amersham) and dried at RT. Non specific interactions were blocked by incubating the membranes with $5 \%$ BSA diluted in PBS for 1 hour at RT. Membrane was probed with biotinylated CTB at a final concentration of $0.1 \mu \mathrm{g} / \mathrm{ml}$ in PBS for $20 \mathrm{~min}$ and, after three washes, was incubated with HRP conjugated Streptavidin (Dako) diluted 1:10,000 in PBS for $20 \mathrm{~min}$.

Signals were developed with the enhanced chemiluminescence detection system kit (Applichem) and detected with Fujifilm LAS3000 Imaging System.

When needed, membranes were stripped by incubating them in stripping buffer ( $2 \%$ SDS, $100 \mathrm{mM} \beta$-mercaptoethanol added fresh, $50 \mathrm{mM}$ Tris-HCl, $\mathrm{pH} 6.8$ ) at $50^{\circ} \mathrm{C}$ for $30 \mathrm{~min}$ with gentle shaking. Membranes were subsequently thoroughly washed in PBS-T and blocked overnight in 5\% dried fat-free milk dissolved in PBS-T before immunoblotting.

\section{Sterol complexes preparation}

7-ketocholesterol (7KC; Sigma) and cholesterol (Sigma) were complexed with methyl- $\beta$-cyclodextrin (M $\beta C D$ ) (Sigma) as previously described in literature [25]. Briefly, sterols were dissolved in $96 \%$ ethanol to a final concentration of $15 \mathrm{mg} / \mathrm{ml}$. M $\beta \mathrm{CD}$ was dissolved in sterile water to a final concentration of $50 \mathrm{mg} / \mathrm{ml}$. $400 \mu \mathrm{l}$ of $50 \mathrm{mg} / \mathrm{ml} \mathrm{M} \beta \mathrm{CD}$ was heated to $80^{\circ} \mathrm{C}$ and $4 \times 10 \mu \mathrm{l}$ of $15 \mathrm{mg} / \mathrm{ml}$ sterols added every $5 \mathrm{~min}$. This preparation led to stock sterols solutions (3.4 mM 7KG, $3.5 \mathrm{mM}$ cholesterol). The compounds were prepared fresh on the day of the experiment.

\section{Fluo-4 AM loading and imaging}

DRG neurons were washed three times with Normal solution (140 mM NaCl, $5 \mathrm{mM} \mathrm{KCl,} 1.8 \mathrm{mM} \mathrm{CaCl} 2,2 \mathrm{mM} \mathrm{MgCl}_{2}$, $10 \mathrm{mM}$ D-Glucose, $10 \mathrm{mM}$ HEPES, pH 7.4) and incubated with $4 \mu \mathrm{M}$ Fluo-4 AM diluted in Normal solution for $30 \mathrm{~min}$ at RT in the dark. After three washes in Normal solution, cells were left $30 \mathrm{~min}$ at RT for the de-esterification step. Following three washes neurons were imaged on a Leica SP5 inverted confocal microscope at $37^{\circ} \mathrm{C}$ in Normal solution. Fluo- 4 was excited with a $488 \mathrm{~nm}$ wavelength and emitted fluorescence was detected in the range $500-570 \mathrm{~nm}$.

\section{Mechano-stimulation}

Mechano-stimulation was performed under manual visual control using a Leica SP5 inverted confocal microscope equipped with micro-manipulator Inject Man N1 2 (Eppendorf). The motorised head of the micro-manipulator was set at $45^{\circ}$ against the main surface of the culture wells and mechano-stimulation of the neurons was achieved by using a fine glass probe with a tip diameter of $1.0 \mu \mathrm{m}$ (Femtotip; Eppendorf). All the experiments were performed in Normal solution in a controlled temperature incubator set at $37^{\circ} \mathrm{C}$.

We probed the neurons three times and for our analysis we defined a neuron as "responsive" if the axonal stimulation evoked a soma response after one of these three stimulations. In case of multiple responses only the first stimulation was included in the analysis, to minimise the effect of sensitisation/desensitisation. Also, the increase of fluorescence at the level of the cell body had to be higher than $10 \%$ (threshold set subjectively) compared to baseline fluorescence to be classified as "response", and had to reach the maximum level within 20 seconds. When a neuron was found to be responsive, the time point of maximum neurite displacement was considered to be the time of probe "contact".
Cells that showed swelling or rupture of the axons upon mechanic stimulation were discarded from the analysis.

\section{Campenot set-up and chemical stimulation}

Campenot chambers were custom designed and fabricated with Teflon (Tyler Research Corporation). The chambers were set-up the day before plating the neurons. Briefly, $35 \mathrm{~mm}$ plastic dishes (BD Falcon) were scratched with a pin-rake in the middle portion and the scratched region was coated with $0.1 \mathrm{mg} / \mathrm{ml}$ poly-Llysine. The middle portion of the scratched region was overlaid with $30 \mu \mathrm{l}$ of $1 \%$ methylcellulose (Sigma), $10 \mu \mathrm{g} / \mathrm{ml}$ laminin (Invitrogen), $50 \mathrm{ng} / \mathrm{ml} \mathrm{NGF}$ diluted in DMEM with antibiotics. The bottom surface of the Teflon dividers was greased with autoclaved high-vacuum grease (Dow Corning). The dividers were sealed to the plastic dishes by turning upside-down the dishchamber complex and by applying gentle pressure to the plastic dishes with a fine forceps. The assembled Campenot chambers were left 2 hours at $37^{\circ} \mathrm{C}$ to equilibrate. $200 \mu \mathrm{l}$ of DMEM was applied to the side chambers and left over-night at $37^{\circ} \mathrm{C}$ to test for leakage. The following day any leaky chambers were discarded.

Chambers were washed three times with pre-warmed DMEM, and coated with $10 \mu \mathrm{g} / \mathrm{ml}$ laminin. 50,000 DRG neurons were plated in DMEM without NGF and supplemented with $10 \% \mathrm{FBS}$, antibiotics, $10 \mu \mathrm{M}$ aphidicolin. Axonal outgrowth was promoted by NGF diluted in 10\% FBS DMEM with antibiotics and $10 \mu \mathrm{M}$ aphidicolin. Experiments were carried out 14 days after plating, when extensive neurite outgrowth in the furthest chamber was obtained.

The day of the experiment DRG neurons were loaded with Fluo-4-AM as described above. For imaging purposes all chambers were filled with $150 \mu \mathrm{l}$ of Normal solution, and axon endings were chemically stimulated with $10 \mu \mathrm{M}$ capsaicin (Fluka), $10 \mu \mathrm{M}$ bradykinin (Sigma) and $300 \mu \mathrm{M}$ ATP (Sigma) diluted in Normal solution. Cell bodies were visualised with a 10x air objective on a Leica SP5 confocal microscope equipped with a heated chamber maintained at $37^{\circ} \mathrm{C}$.

Neurons that showed a transient increase of fluorescence higher than $3 \%$ above baseline upon chemical stimulation, were classified as responsive. This value was chosen as it represents at least three times the increase that occurred in a few control cells following vehicle application ( $1 \%$ increase in 1 out of 58 cells). Also, the increase of fluorescence had to show a transient profile to be classified as positive. Cells showing an oscillation in fluorescence before the chemical stimulation were excluded from the analysis.

\section{Results}

\section{$\mathrm{Na}_{\mathrm{v}} 1.8$ localises in clusters along the axons of cultured small diameter DRG neurons}

We first analysed the sub-cellular distribution of $\mathrm{Na}_{\mathrm{V}} 1.8$ in DRG neurons in vitro by immunocytochemistry. After two days in vitro (DIV), DRG neurons showed an extensive neurite outgrowth and we found that, in small-diameter cell body neurons $(<25 \mu \mathrm{m})$, most likely to be nociceptors [26,27], $\mathrm{Na}_{\mathrm{V}} 1.8$ was expressed both at the level of the cell body (Figure 1A, asterisk) and along the neurites, where in the latter location it was distributed in a clustered fashion (Figure 1A, arrows; mean length of the clusters $\pm \mathrm{SEM}=3.38 \pm 0.40 \mu \mathrm{m} ; \mathrm{n}=3$; Total clusters counted $=255$ ). The phase contrast image in Figure 1A, and the magnified inset, show that $\mathrm{Na}_{\mathrm{V}} 1.8$ immunoreactivity was associated with intact neurons, and that the clustered appearance in small-diameter neurons was not due to uneven morphology of the axons (e.g. rupture due to necrosis, apoptosis). To further confirm $\mathrm{Na}_{\mathrm{V}} 1.8$ sub-cellular distribution in vitro we performed double immunocy- 
tochemistry between $\mathrm{Na}_{\mathrm{V}} 1.8$ and Peripherin (a marker of smalldiameter, unmyelinated nociceptors). In agreement with the findings for neurons discriminated only in terms of their cell body diameters, $\mathrm{Na}_{V} 1.8$ was found to be localised along the neurites in distinguishable puncta in Peripherin-positive small-diameter neurons (Figure 1B, arrows). We found also that a minor population of large-diameter neurons expressed $\mathrm{Na}_{\mathrm{V}}$ 1.8. In these cells $\mathrm{Na}_{\mathrm{V}} 1.8$ was either evenly distributed or associated in large patches (Figure S1 A, B).

To eliminate the possibility that the clusters of $\mathrm{Na}_{\mathrm{V}} 1.8$ were due to artificial aggregation elicited by the antibody, we analysed the $\mathrm{Na}_{\mathrm{V}} 1.8$ sub-cellular localisation by using a fluorescent version of $\mathrm{Na}_{\mathrm{V}}$ 1.8. We cloned the fluorescent tag DsRed2 to the C-terminus of $\mathrm{Na}_{\mathrm{V}} 1.8$ to create the fusion protein $\mathrm{Na}_{\mathrm{V}} 1.8$-DsRed2 under the influence of CMV immediate early promoter. By mean of electroporation we delivered the plasmid DNA into the DRG neurons and monitored $\mathrm{Na}_{\mathrm{V}}$ 1.8-DsRed2 fluorescence. We found that $\mathrm{Na}_{\mathrm{V}} 1.8-\mathrm{DsR}$ ed2 showed a clustered localisation in neurons along the axons (Figure 1C, left panel), similar to that shown by the antibody-based technique we previously described. Densitometric analysis of $\mathrm{Na}_{\mathrm{V}}$ 1.8-DsRed2 fluorescence along the axon of the DRG neuron showed that clear peaks of fluorescence appeared along the axon length (Figure 1C, right panel).

We also investigated $\mathrm{Na}_{\mathrm{V}} 1.8$ distribution along the axons of small-diameter, unmyelinated fibres ex vivo. In small-diameter fibres, identified both by low contrast in bright-field imaging (Figure 2A, arrow) and by positive immunolabelling for Peripherin (Figure 2B), $\mathrm{Na}_{\mathrm{V}} 1.8$ showed a clustered distribution (Figure 2A, B), similar to that identified in the in vitro preparations.

\section{$\mathrm{Na}_{\mathrm{V}} 1.8$ clusters co-localise with lipid raft markers in DRG neurons in vitro}

Our findings indicated that $\mathrm{Na}_{\mathrm{V}} 1.8$ was distributed in a punctuate fashion in the processes of unmyelinated neurons, and we hypothesised that it localises within the membrane micro-domains known as lipid rafts. Lipid rafts have already been described as microdomains in which sub-populations of specialised proteins are known to cluster $[28,29]$. Lipid rafts by definition have a distinctive lipid make-up, where ganglioside GM1 is highly enriched and is a standard marker of these micro-domains [30]. To investigate the association between $\mathrm{Na}_{\mathrm{V}} 1.8$ and lipid rafts in vitro we have visualised gangliosides GM1 by Cholera Toxin B subunit (CTB), and localised $\mathrm{Na}_{\mathrm{V}} 1.8$ by immunocytochemistry.

At the sub-cellular level we found that GM1 is present as puncta on the cell surface of the cell body (Figure $3 \mathrm{~A}$ ) and along the axons of DRG neurons (Figure 3B) after two DIV. At the level of the cell bodies $\mathrm{Na}_{\mathrm{V}} 1.8$ and GM1, did not show a clear co-localisation; it was possible to distinguish clear puncta for GM1, but $\mathrm{Na}_{V} 1.8$ immunoreactivity was evenly distributed and occasionally aggregated in brighter patches (Figure 3A). However, along the neurites, GM1 and $\mathrm{Na}_{\mathrm{V}} 1.8$ showed a convincing pattern of association. Figure 3B shows a representative intact neurite with clusters of $\mathrm{Na}_{\mathrm{V}} 1.8$ co-localising with GM1 puncta (arrows). It is noteworthy to highlight that the phase contrast image shows an intact morphology of the neurite and that the puncta are not associated with varicosities or bulges of the membrane. We found that the majority of $\mathrm{Na}_{\mathrm{V}} 1.8$ clusters co-localised with clusters of GM1 $\left(80.5 \% \pm 6.3\right.$ of $\mathrm{Na}_{\mathrm{V}} 1.8$ clusters positive for $\mathrm{GM} 1 ; \mathrm{n}=3$, total number of clusters counted $=182$ ) (Figure 3B, arrows).

We also used the $\mathrm{Na}_{\mathrm{V}} 1.8-\mathrm{D}$ sRed2 construct to further investigate the co-localisation of $\mathrm{Na}_{\mathrm{V}} 1.8$ with lipid rafts along the neurites. We report that the clusters of $\mathrm{Na}_{\mathrm{V}} 1$.8-DsRed2 also colocalised with GM1 (Figure 1C, left panel), thereby confirming the previous immunocytochemical finding with the endogenous channel, and showing that the addition of a fluorescent tag to $\mathrm{Na}_{V} 1.8$ neither disrupts its ability to cluster nor to co-localise with GM1. Even though DsRed2 displays faster maturation compared to wild type red fluorescent protein, we confirmed that the colocalisation between GM1 and $\mathrm{Na}_{\mathrm{V}}$ 1.8-DsRed2 is not due to the maturation of DsRed2, which may undergo a green fluorescent state (Figure S2).

Lipid rafts are heterogeneous micro-domains and two distinct types have been described: planar and caveolae-type. Flotillin- 1 is enriched in planar lipid rafts [31] and in neuronal cells it is present in non caveola-type rafts [32] while Caveolin-2 is present in caveolae-type lipid rafts [33]. In order to ascertain if $\mathrm{Na}_{\mathrm{V}} 1.8$ shows different partitioning between planar and caveolae-type we tagged the C-terminus of Flotillin-1 and Caveolin-2 with the green photochromic fluorescent protein Dronpa [34] and delivered the plasmid DNA to DRG neurons. To analyse the degree of colocalisation between endogenous $\mathrm{Na}_{\mathrm{V}} 1.8$ and these lipid raft markers we detected $\mathrm{Na}_{\mathrm{V}} 1.8$ by immunocytochemistry. We found that endogenous $\mathrm{Na}_{\mathrm{v}} 1.8$ showed a higher percentage of colocalisation with Flotillin-1-Dronpa (planar rafts), compared to Caveolin-2-Dronpa (caveolae rafts) (Figure S3 A, B).

\section{$\mathrm{Na}_{\mathrm{v}} 1.8$ co-purifies with lipid rafts in vivo and in vitro, and $\mathrm{Na}_{\mathrm{V}}$ 1.8-raft association in vitro is impaired by M $\mathrm{MCD}$ and 7KC treatments}

Lipid rafts, due to their biophysical features, are resistant to non-ionic detergents at $4^{\circ} \mathrm{C}$, a property that can be exploited to separate them from the soluble portion of the membrane (nonlipid raft) by ultra-centrifugation on a density gradient $[16,35,36,37]$. Because we found that $\mathrm{Na}_{\mathrm{V}} 1.8$ co-localised with lipid and protein raft markers in vitro, we hypothesised that $\mathrm{Na}_{\mathrm{V}} 1.8$ may associate with lipid rafts. We therefore analysed its partition between lipid rafts and the soluble fraction from sciatic nerve $e x$ vivo and cultured DRG neurons, to provide further evidence for this association.

The sciatic nerve is a spinal nerve which contains the axons of sensory and motor neurons, whose cell bodies are located in the DRGs and ventral horn of the spinal cord, respectively. Since $\mathrm{Na}_{\mathrm{V}} 1.8$ is localised in the unmyelinated axons of the sciatic nerve [38] we tested if $\mathrm{Na}_{\mathrm{V}} 1.8$ exists in the lipid raft fraction of the sciatic nerve after OptiPrep gradient centrifugation. In this study, we used a protein and a lipid marker, Flotillin-1 and GM1 respectively, to define the floating, low density, raft fraction. We found that Flotillin-1 was present as two pools: one associated with the bottom fractions (lanes 8 and 9) and one associated with the top fractions (lanes 2, 3 and 4) (Figure 4). GM1 was highly enriched in the top fraction (lanes 2, 3 and 4). To define the nonlipid raft portion of the membrane we used Transferrin receptor, which is widely used as a non-raft marker [30]. Transferrin receptor was only found in the bottom fractions (lanes 8 and 9). Given the distribution of these markers, we defined fractions 2, 3 and 4 as the lipid raft fraction and fractions 8 and 9 as the soluble portion of the membrane (Figure 4). We next evaluated $\mathrm{Na}_{\mathrm{V}} 1.8$ partitioning in this preparation of the sciatic nerve, and remarkably $\mathrm{Na}_{\mathrm{V}} 1.8$ was found only in the raft fraction (lanes 2 and 3); no $\mathrm{Na}_{V} 1.8$ was associated with the soluble fraction (Figure 4). Of note, $\mathrm{Na}_{\mathrm{V}} 1.8$ was present at slightly different sizes in lanes 2 and 3, which may represent different glycosylation states of the channel $[39,40,41]$. Interestingly it has been reported that different glycosylation states may act as sorting signals for raft association $[42,43,44]$.

In contrast, when we performed OptiPrep gradient centrifugation with freshly extract DRG tissue, containing the nerve cell bodies, $\mathrm{Na}_{\mathrm{V}} \mathrm{l} .8$ was mostly associated with the soluble fraction and 


\section{A}
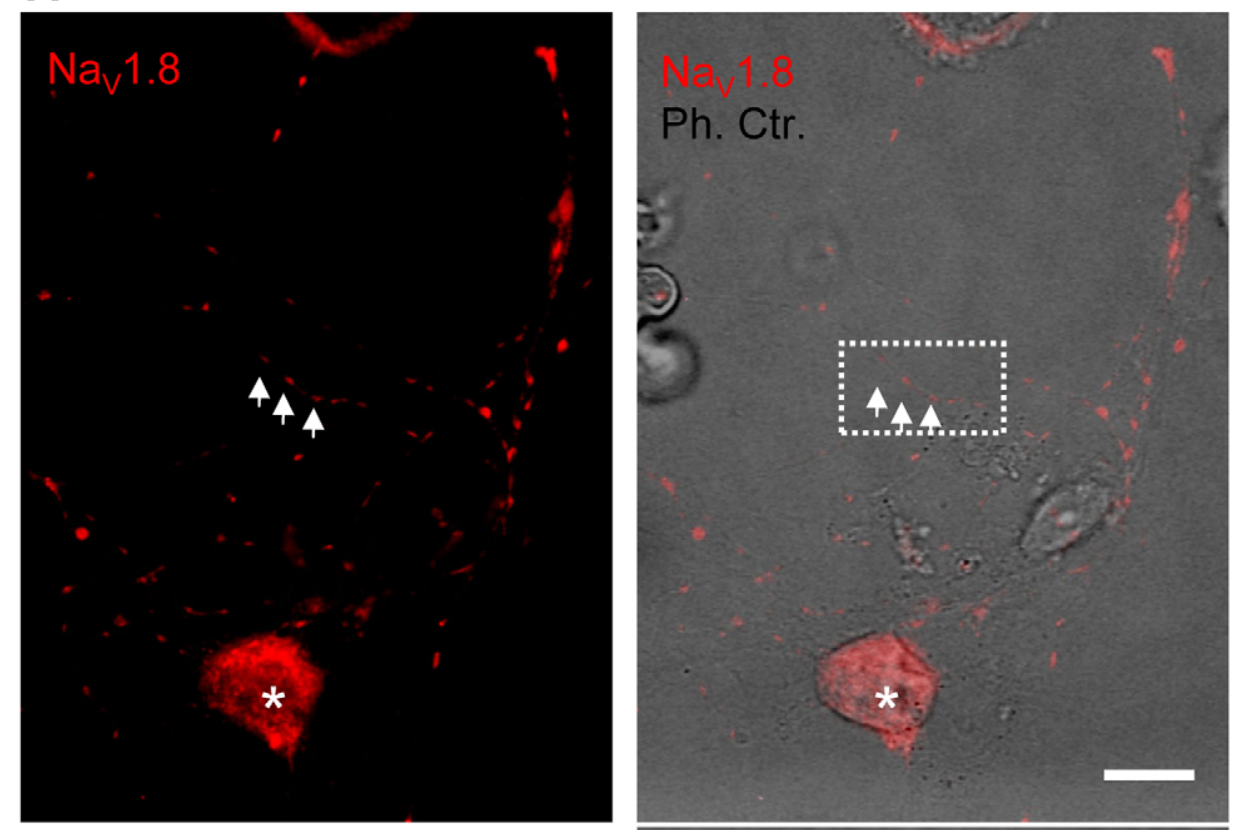

B
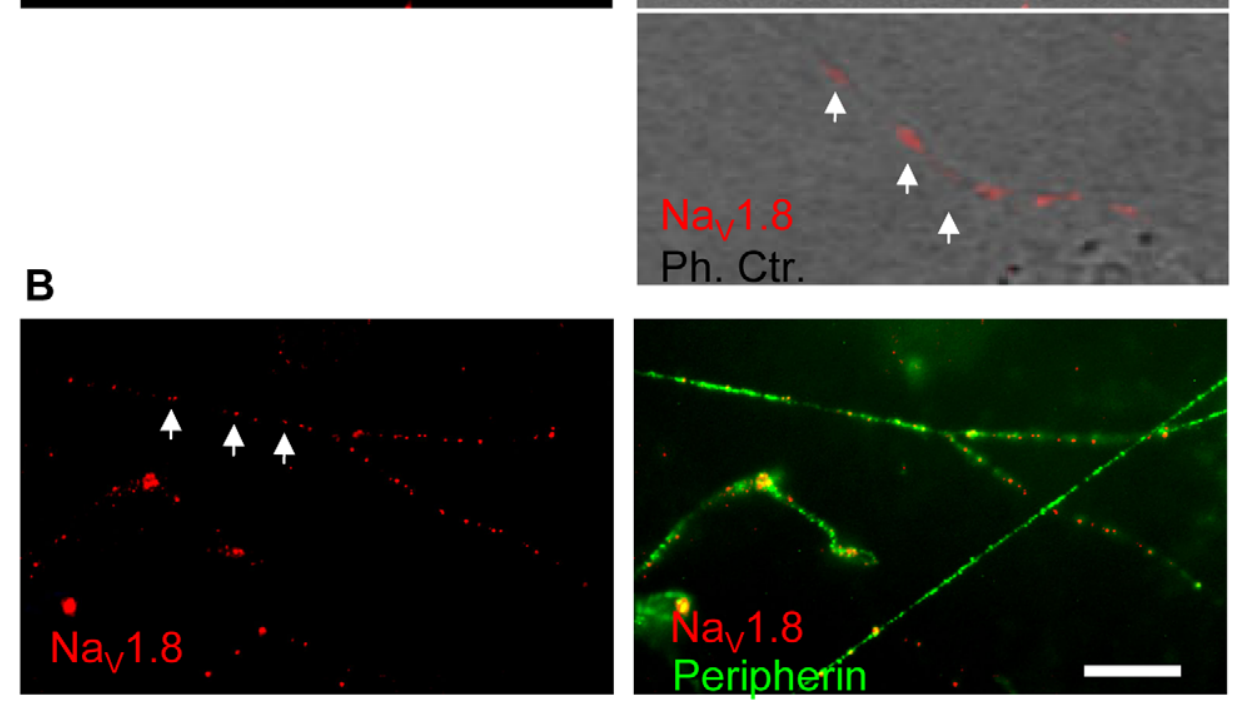

\section{C}
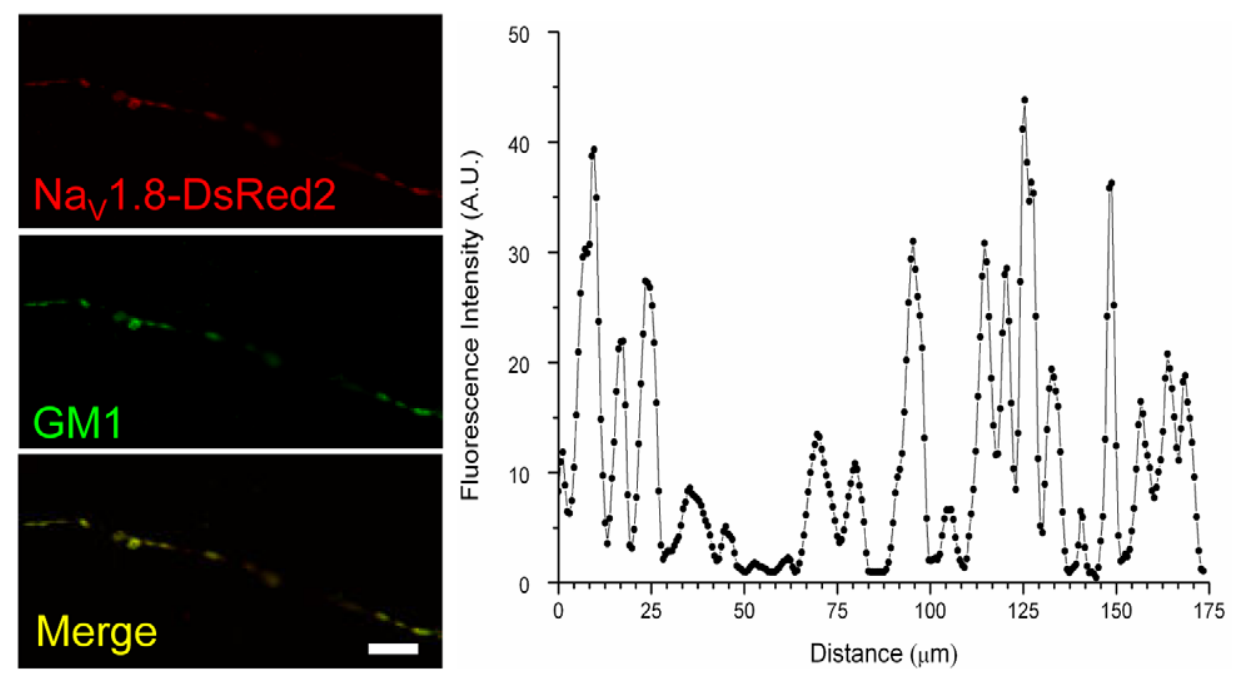
Figure 1. $\mathrm{Na}_{\mathrm{v}} \mathrm{1.8}$ is distributed in clusters along the axons of small, unmyelinated DRG neurons in vitro. Endogenous $\mathrm{Na}_{\mathrm{v}} 1.8$ was immuno-localised in cultured DRG neurons after 2 DIV. Small-diameter neurons were identified by morphology (A, right panel) and by the immunoreactivity for Peripherin ( $B$, right panel). The region framed by the dotted square in $A$ is magnified in the inset below. Nav 1.8 is distributed in distinct puncta along the neurites, of small-diameter neurons (A, B; arrows pinpoint example of clusters, which are distributed throughout the neurites). Nav1.8 was also found to be enriched at the level of the cell bodies (Figure 1A, asterisk). The fluorescent construct Nav1.8-DsRed2 was visualised in DRG neurons. The image shows Nav1.8-DsRed2 distributed in clusters along the axon of DRG neuron (C, left panel). The discontinuous distribution of the fluorescent construct has been mapped by quantifying pixel intensity along the neurite $(C$, graph; right panel). Also, the fluorescent construct $\mathrm{Na}_{\mathrm{V}}$ 1.8-DsRed2 colocalises with GM1 puncta along the neurite of DRG neurons, as shown by the superimposed images of Nav1.8-DsRed2 and GM1 (merge). Scale bars are $20 \mu \mathrm{m}$.

doi:10.1371/journal.pone.0040079.g001

only a minor amount of $\mathrm{Na}_{\mathrm{V}} 1.8$ could be detected in the lipid raft fraction (data not shown). To summarise, $\mathrm{Na}_{\mathrm{V}} 1.8$ was mainly localised in the lipid rafts fraction of sciatic nerves, while Nav1.8 was located in the non-raft portion of the cell bodies of DRG neurons.

Similarly to the DRG and sciatic nerve ex vivo preparations, we separated lipid rafts from DRG neurons cultured for two DIV. From this source we found that the majority of Flotillin-1 was recovered from the low density fractions (Figure 5A, lanes 2 and 3). GM1 associated with top (Figure 5A, lanes 2 and 3) and bottom fractions (Figure 5A, lanes 7, 8 and 9). Transferrin receptor, as expected, did not display raft-like properties and was retained in the soluble fraction (Figure 5A, lanes 7, 8 and 9). These data clearly show that cultured DRG neurons, similar to sciatic nerve in vivo, contain lipid rafts which can be extracted from the soluble fraction. Therefore, from plated DRG neurons, by density gradient, lipid rafts were defined by floating fractions 2 and 3 . We investigated $\mathrm{Na}_{V} 1.8$ co-purification with rafts after two DIV and found that $\mathrm{Na}_{\mathrm{V}} 1.8$ was clearly associated both with the lipid raft (Figure 5A, lane 2) and the non-lipid raft (Figure 5A, lanes 7, 8 and 9) fractions.

Lipid raft integrity is dependent on the presence of cholesterol, and the depletion of cholesterol from the cell membrane by Methyl- $\beta$-cyclodextrin (M $\beta \mathrm{CD}$ ) leads to their disruption. In addition, lipid rafts are liquid ordered micro-domains and the delivery of a cholesterol analogue, 7-ketocholesterol $(7 \mathrm{KG})$, to cell membrane has also been found to negatively affect raft stability $[25,45,46]$.

For the purpose of interfering with raft integrity, we incubated DRG neurons, cultured for two DIV, with either $10 \mathrm{mM} \mathrm{M} \beta \mathrm{CD}$ or $50 \mu \mathrm{M} 7 \mathrm{KC}$ (delivered as a complex with M $\beta \mathrm{CD}$; see the

A

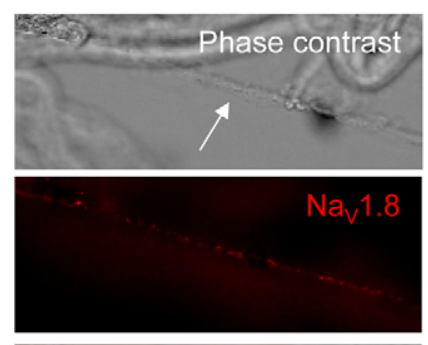

Merge

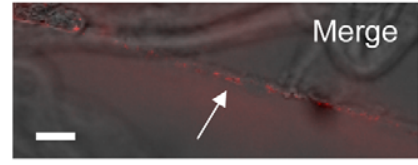

\section{B}

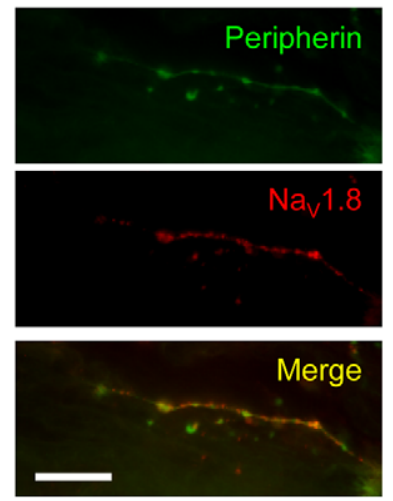

Figure 2. $\mathrm{Na}_{\mathrm{v}} 1.8$ is distributed in clusters along the axons of small, unmyelinated DRG neurons in vivo. $\mathrm{Na}_{v} 1.8$ is clustered in puncta along the unmyelinated fibres of rat sciatic nerve. Teased unmyelinated fibres were identified by morphology ( $A$, arrow) and by immuno-reactivity for Peripherin (B). Scale bars are $20 \mu \mathrm{m}$. doi:10.1371/journal.pone.0040079.g002
Materials and Methods) for $30 \mathrm{~min}$ at $37^{\circ} \mathrm{C}$. M $\mathrm{MCD}$ and $7 \mathrm{KC}$ were used to deplete cholesterol from the neurons and to disrupt the lipid ordered phase of neuronal rafts, respectively. Control cells were left untreated (CTR). We assessed how raft stability and $\mathrm{Na}_{\mathrm{V}} 1.8$ association with rafts were affected by detergent extraction and ultracentrifugation. We found that $10 \mathrm{mM} \mathrm{M} \beta \mathrm{CD}$, and $50 \mu \mathrm{M} 7 \mathrm{KC}$ negatively affected raft stability. In fact, upon detergent extraction, Flotillin-1 profiles between $7 \mathrm{KC}, \mathrm{M} \beta \mathrm{CD}$ and CTR were different. In the CTR condition (Figure 5A), the majority of Flotillin-1, as described before, was retrieved from the top fractions (lanes 2 and 3). However, in 7KG-treated neurons Flotillin-1 displayed a reduced amount on the top fractions (Figure 5B, lanes 2 and 3) and a tailing effect towards the bottom fractions. In $\mathrm{M} \beta \mathrm{CD}$ treated samples, lipid raft disruption was also evident, with Flotillin-1 being recovered mostly from the bottom fractions (Figure 5C, lanes 7, 8 and 9) (By densitometric analysis of Flotillin-1 western blot bands we quantified the mean value of Flotillin-1 pool associated with the raft fraction in $7 \mathrm{KG}$ and M CCD-treated samples. Mean value expressed as \% of raft associated Flotillin-1 in CTR samples $\pm \mathrm{SD} ; 7 \mathrm{KC}=46.7 \% \pm 24.8$; $\mathrm{M} \beta \mathrm{CD}=30.9 \% \pm 24.8)$. We also probed $7 \mathrm{KC}$ and $\mathrm{M} \beta \mathrm{CD}$ treated samples for GM1. The dot blots in Figure $5 \mathrm{~B}$ and $5 \mathrm{C}$ show an accumulation of GM1 in the bottom fractions and a reduction in the raft fractions, consistent with raft disruption (Figure 5B, 5C). We further investigated $\mathrm{M} \beta \mathrm{CD}$ and $7 \mathrm{KC}$ effects by imaging techniques. By using the lipid phase sensitive probe di-4ANEPPDHQ [47,48] (Method S1) we found that both M $\beta C D$ and $7 \mathrm{KC}$ treatments altered the lipid phase of DRG neurons, shifting it to a less ordered state, consistent with raft disruption (Figure S4). We next probed these samples for $\mathrm{Na}_{\mathrm{V}} 1.8$, to ascertain its partitioning upon raft depletion. Remarkably we found that, compared to CTR sample, all $\mathrm{Na}_{\mathrm{V}} 1.8$ was recovered from the bottom, non-raft fractions. In fact, the lipid raftassociated pool (lane 2 in CTR), was absent in both $7 \mathrm{KC}$ - and M $\beta C$ D-treated samples (Figure $5 \mathrm{~B}, \mathrm{C}$ ), indicating that treatment with $\mathrm{M} \beta \mathrm{CD}$ and $7 \mathrm{KC}$ leads to the dissociation of $\mathrm{Na}_{\mathrm{V}} 1.8$ from lipid rafts (By densitometric analysis of $\mathrm{Na}_{\mathrm{V}} 1.8$ western blot bands we quantified the mean value of $\mathrm{Na}_{\mathrm{V}} 1.8$ pool associated with the raft fraction in $7 \mathrm{KC}$ and $\mathrm{M} \beta \mathrm{CD}$-treated samples. Mean value expressed as \% of raft associated $\mathrm{Na}_{\mathrm{V}} 1.8$ in CTR samples \pm $\mathrm{SD} ; 7 \mathrm{KC}=5.7 \% \pm 1.1 ; \mathrm{M} \beta \mathrm{CD}=3.5 \% \pm 0.1)$.

In summary, we have demonstrated that $\mathrm{Na}_{\mathrm{V}} 1.8$ co-purifies with lipid rafts in vitro and along the axons of sensory neurons $e x$ vivo. We also demonstrated that after $\mathrm{M} \beta \mathrm{CD}$ and $7 \mathrm{KC}$ treatments $\mathrm{Na}_{\mathrm{V}}$ 1.8-raft association is negatively affected.

We sought to investigate if lipid raft disruption had an effect on $\mathrm{Na}_{V} 1.8$ sub-cellular localisation. After two DIV we treated neurons with $10 \mathrm{mM} \mathrm{M} \beta \mathrm{CD}$ or $50 \mu \mathrm{M} 7 \mathrm{KC}$ for $30 \mathrm{~min}$ at $37^{\circ} \mathrm{C}$. CTR cells were left untreated or treated with $50 \mu \mathrm{M}$ cholesterol (CHOL). After the treatments, neurons were fixed and processed for immunofluorescence. We found that the different treatments did not induce macroscopic alteration in $\mathrm{Na}_{V} 1.8$ distribution (Figure S5). 
A
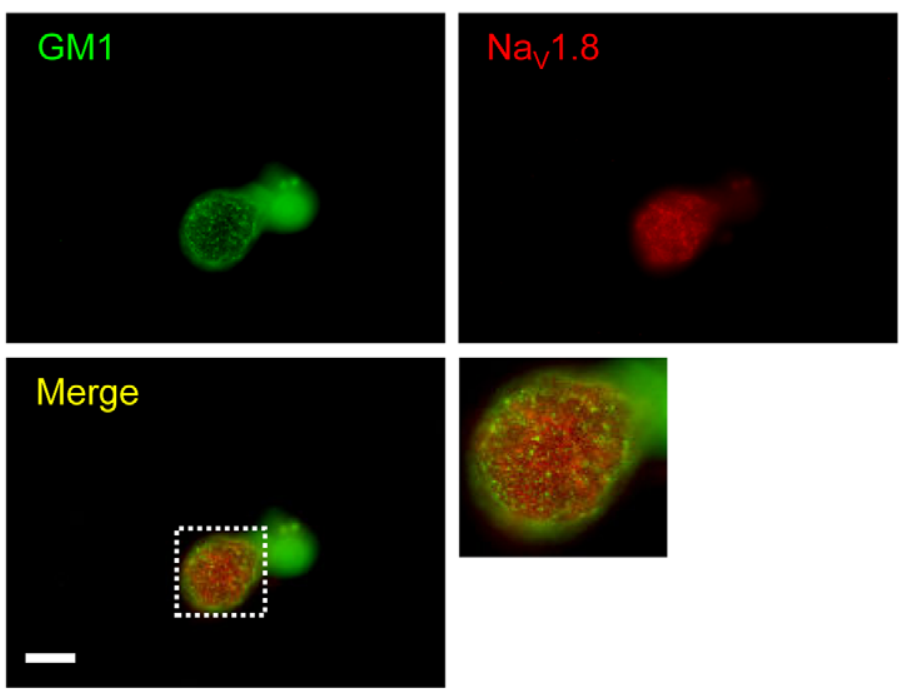

B
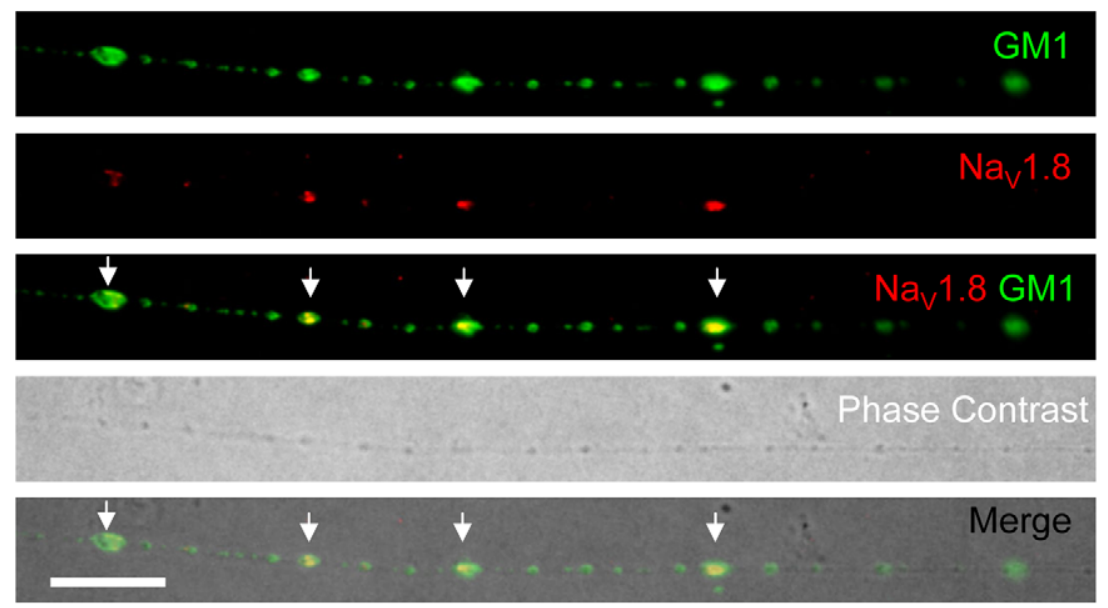

Figure 3. Nav1.8 clusters colocalise with GM1 along the axons of small DRG neurons in vitro. Endogenous Nav1.8 was immuno-localised in cultured DRG neurons after 2 DIV. GM1 molecules were detected with CTB. At the level of the cell bodies there is no clear colocalisation between endogenous Nav1.8 and GM1 molecules (A). In contrast, along the neurites Nav1.8 clusters colocalise with GM1 puncta (arrows, B). Phase contrast image in B demonstrates the integrity of the neurite. Scale bars are $20 \mu \mathrm{m}$. doi:10.1371/journal.pone.0040079.g003

\section{Lipid raft disruption negatively affects the propagation of mechanically-induced depolarisations in DRG neurons in vitro}

Because $\mathrm{Na}_{\mathrm{V}} 1.8$ mediates action potential generation and propagation in DRG neurons we developed two assays to study the effect of raft depletion and concomitant $\mathrm{Na}_{\mathrm{V}} 1.8$ shift to the liquid disordered phase on action potential propagation in these neurons.

We firstly developed an assay based on mechano-stimulation to study action potential propagation. Some DRG sensory neurons are mechano-sensitive in vivo $[49,50]$ and they retain the property to trigger action potentials, in response to mechanical stimuli, in vitro $[51,52,53,54,55]$. We exploited this ability to study action potential propagation in cultured DRG neurons. It has been demonstrated that real-time imaging of calcium fluxes in cell bodies of sensory neurons reliably reects action potential firing patterns [56]. DRG neurons cultured for two DIV were loaded with calcium indicator Fluo-4 [57,58]. We mechanically stimulated the neurites of the cells using a glass probe (Figure 6A, right panel), to evoke action potentials, and recorded subsequent changes in Fluo-4 fluorescent intensity in three regions of interest (ROI), ROI1 (cell soma), ROI2 (distal part of the neurite), and ROI3 (proximal part of the neurite) (Figure 6A, left panel). We found that when the glass probe contacted the neurite of a responsive neuron, an increase of Fluo-4 fluorescence was detected at the level of the neurite and this increase in fluorescence was propagated from the point of contact, in both an antidromic and orthodromic fashion, towards the end of the neurite and the cell body, respectively. When the wave of fluorescence reached the cell body, it responded with a sharp increase of fluorescence (Figure 6B). Figure 6C shows the recorded fluorescence intensity of different ROIs in a transient manner. For this series of experiments we probed axons originating from small-diameter neurons (diameter $<25 \mu \mathrm{m}$ ), most likely to be nociceptive, at 
Sciatic nerve ex vivo
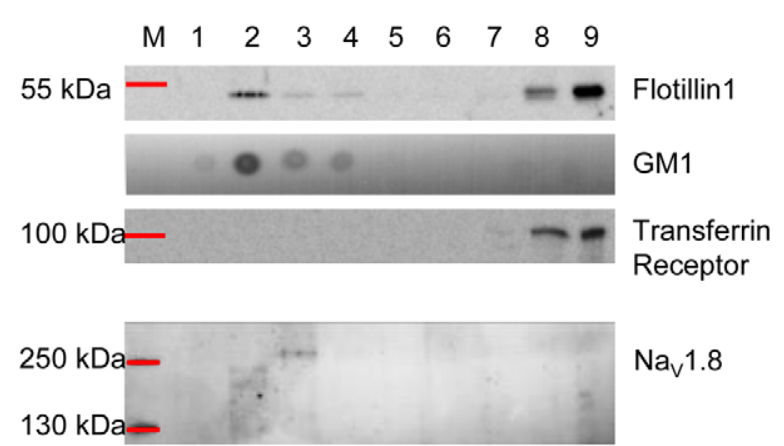

Figure 4. $\mathrm{Na}_{\mathrm{v}} \mathrm{1.8}$ associates with lipid rafts in the sciatic nerve. Lipid rafts were extracted from the sciatic nerve. After centrifugation on an lodixanol density gradient, fractions were analysed by western blotting and dot blot analysis to assess lipid raft isolation and $\mathrm{Na}_{\mathrm{v}} 1.8$ partitioning between lipid rafts and the non-raft portions of the membrane. Flotillin1 and GM1 were used as a protein and lipid marker of lipid rafts, respectively. Transferrin receptor was used as a marker of non-raft portions. In the sciatic nerve the totality of $\mathrm{Na}_{v} 1.8$ is associated with lipid rafts. $M$ represents protein ladder, the recovered fractions are numbered from 1 (top fraction) to 9 (bottom fraction).

doi:10.1371/journal.pone.0040079.g004

a mean distance of $19.8 \pm 7.6 \mu \mathrm{m}$ from the cell soma. The increase in intracellular calcium in the cell soma, upon mechanical stimulation of the neurite, was most likely due to influx of extracellular calcium, rather than release from intracellular calcium stores, as no increase in Fluo-4 fluorescence was detected when stimulation was performed in calcium-free conditions and in the presence of $2 \mathrm{mM}$ EGTA $(\mathrm{n}=8$, Table 1$)$. To further clarify that the calcium increase in cell soma, upon axonal mechanostimulation, was caused by membrane depolarisation propagated through VGSCs, we investigated soma responsiveness upon mechanical stimulation of the neurite in sodium-free conditions. We replaced extracellular $\mathrm{NaCl}$ with an equimolar amount of choline chloride to maintain correct osmolarity [59] and ionic strength of the medium. Importantly, in this condition we did not detect any somal responses upon mechanical stimulation of the axons $(\mathrm{n}=15$; Table 1$)$. We further characterised the nature of the propagating depolarisation from the axon to the cell body, by performing the experiment in the presence of lidocaine or TTX. Given the criteria of acceptance described in the Materials and Methods, we found that, in the presence of $500 \mu \mathrm{M}$ lidocaine, the percentage of responsive cells dropped significantly compared to control cells $(\%$ of responsive cells; CTR $=50.9 \%$, lidocaine $500 \mu \mathrm{M}=0 \% * *=\mathrm{p}<0.05$ vs. CTR. Fisher's exact test; Table 1). These data clearly indicate that VGSGs are needed for the propagation of evoked depolarisations towards the cell body and for its subsequent increase in intracellular calcium. The presence of $250 \mathrm{nM}$ TTX, however, did not affect the cell responsiveness, suggesting that TTX-r VGSC channels (e.g. Nav1.8) are sufficient to allow the propagation of depolarisations and cell soma responsiveness $(\%$ of responsive cells; CTR $=50.9 \%$, TTX $250 \mathrm{nM}=50 \%$; Table 1).

We used the mechano-stimulation based assay to study action potential propagation after lipid raft disruption, a scenario in which we previously demonstrated that $\mathrm{Na}_{\mathrm{V}} 1.8$ shifts from the raft fraction to the soluble fraction. We treated the cells with $50 \mu \mathrm{M}$ $7 \mathrm{KC}$ or $10 \mathrm{mM} \mathrm{M} \beta \mathrm{CD}$ to disrupt lipid rafts. CHOL cells were treated with $50 \mu \mathrm{M}$ cholesterol and CTR cells left untreated. In these conditions we found that cholesterol-treated cells were as
DRG neurons in vitro

A)

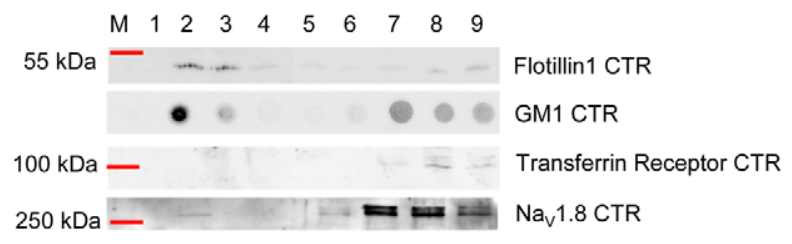

B)

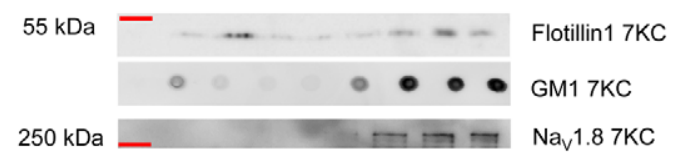

C)

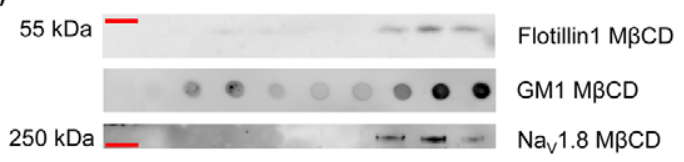

Figure 5. $\mathrm{Na}_{\mathrm{v}} \mathrm{1.8}$ associates with lipid rafts in DRG neurons in vitro. Lipid rafts were extracted from DRG neurons after 2 DIV. After centrifugation on an lodixanol density gradient fractions were analysed by western blotting and dot blot analysis to assess lipid raft isolation and $\mathrm{Na}_{\mathrm{v}} 1.8$ partitioning between lipid rafts and the non-raft portions of the membrane. Flotillin 1 and GM1 were used as a protein and lipid marker of lipid rafts, respectively. Transferrin receptor was used a marker of non-raft portions. Nav1.8 is associated with both lipid rafts and nonraft portions of the membrane (A). Incorporation of 7KC into the neuronal plasma-membranes impairs lipid raft stability. In this condition total $\mathrm{Na}_{\mathrm{v}} 1.8$ is associated with the non-raft portion of the membrane (B). Depletion of cholesterol from the neuronal membrane, by using $M \beta C D$, leads to lipid rafts disruption. $\mathrm{Na}_{\mathrm{v}} 1.8$ is only associated with the soluble, non-raft, portion of the membrane upon this treatment (C). M represents protein ladder, the recovered fractions are numbered from 1 (top fraction) to 9 (bottom fraction).

doi:10.1371/journal.pone.0040079.g005

responsive as control cells. Remarkably, upon lipid raft disruption and $\mathrm{Na}_{\mathrm{V}} 1.8$ redistribution to the soluble fraction of the cell membrane, we found a significant decrease in the number of soma able to respond to mechanical stimulation of the axon $(\%$ of responsive cells; CTR $=50.9 \%, \mathrm{n}=55 ; 50 \mu \mathrm{M}$ CHOL $=54.2 \%$, $\mathrm{n}=24 ; 50 \mu \mathrm{M} 7 \mathrm{KC}=27.8 \% *, \mathrm{n}=36 ; 10 \mathrm{mM} \mathrm{M} \beta \mathrm{CD}=27.8 \% *$, $\mathrm{n}=36 . *=\mathrm{p}<0.05$ vs. CTR using Fisher's exact test. Table 1).

The mechano-stimulation based assay allowed us to calculate the time between mechano-stimulation and somal response. Since the distance between the site of stimulation and the cell soma was also known, we calculated the mean speed of conduction of Fluo-4 signals, between the point of stimulation on the axon and the cell body. We found that, compared to control conditions, the mean speed of conduction was significantly lower upon lipid raft disruption. Cholesterol treatments had no effect (mean speed (in $\mu \mathrm{m} / \mathrm{sec}) \pm \mathrm{SEM}: \mathrm{CTR}=20.8 \pm 2.1, \mathrm{n}=28 ; \mathrm{CHOL}=19.1 \pm 3.4$, $\mathrm{n}=13 ; 7 \mathrm{KC}=12.3 \pm 2.2^{*}, \mathrm{n}=10 ; \mathrm{M} \beta \mathrm{CD}=12.4 \pm 2.6^{*}, \mathrm{n}=10 ;$ $*=p<0.05$ vs. CTR., Mann-Whitney U Test; Figure 7). It should be noted that this conduction velocity is not signifying the speed of action potential propagation itself, but the speed of conduction of Fluo-4 fluorescent signals. Although this phenomenon might be dependent upon actual velocity of action potential propagation, there are also other factors involved, e.g. activation kinetics of voltage-gated calcium channels in response to membrane depolarisation, speed of Fluo-4 response to the increase of calcium concentration, and of course the property of mechano-transducers. 
A
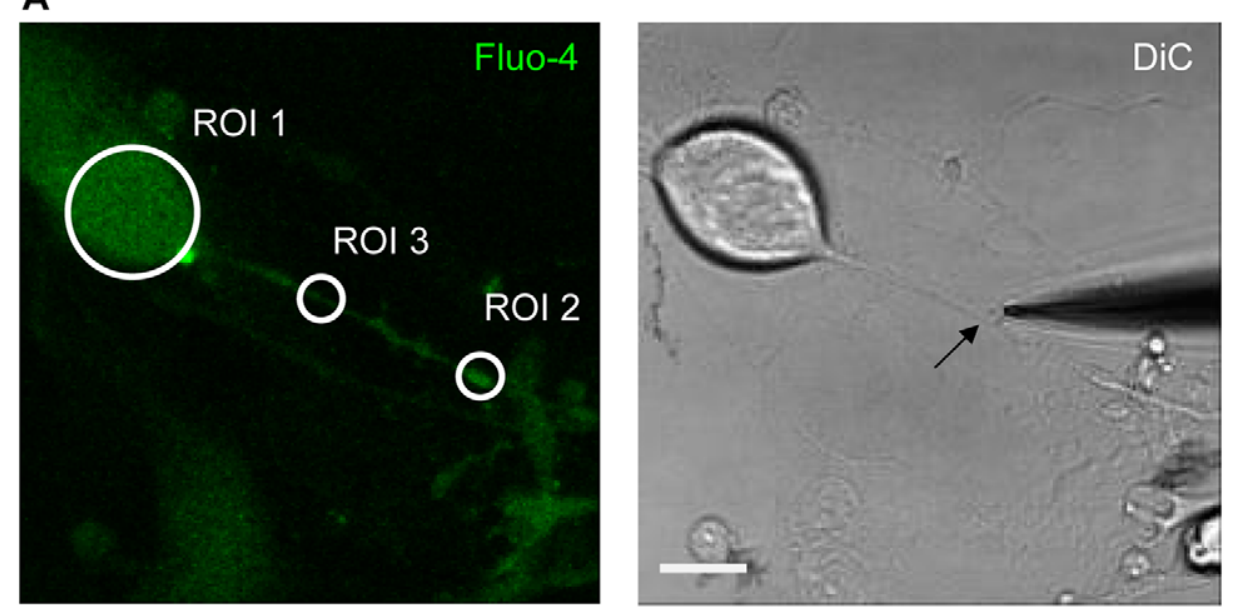

B
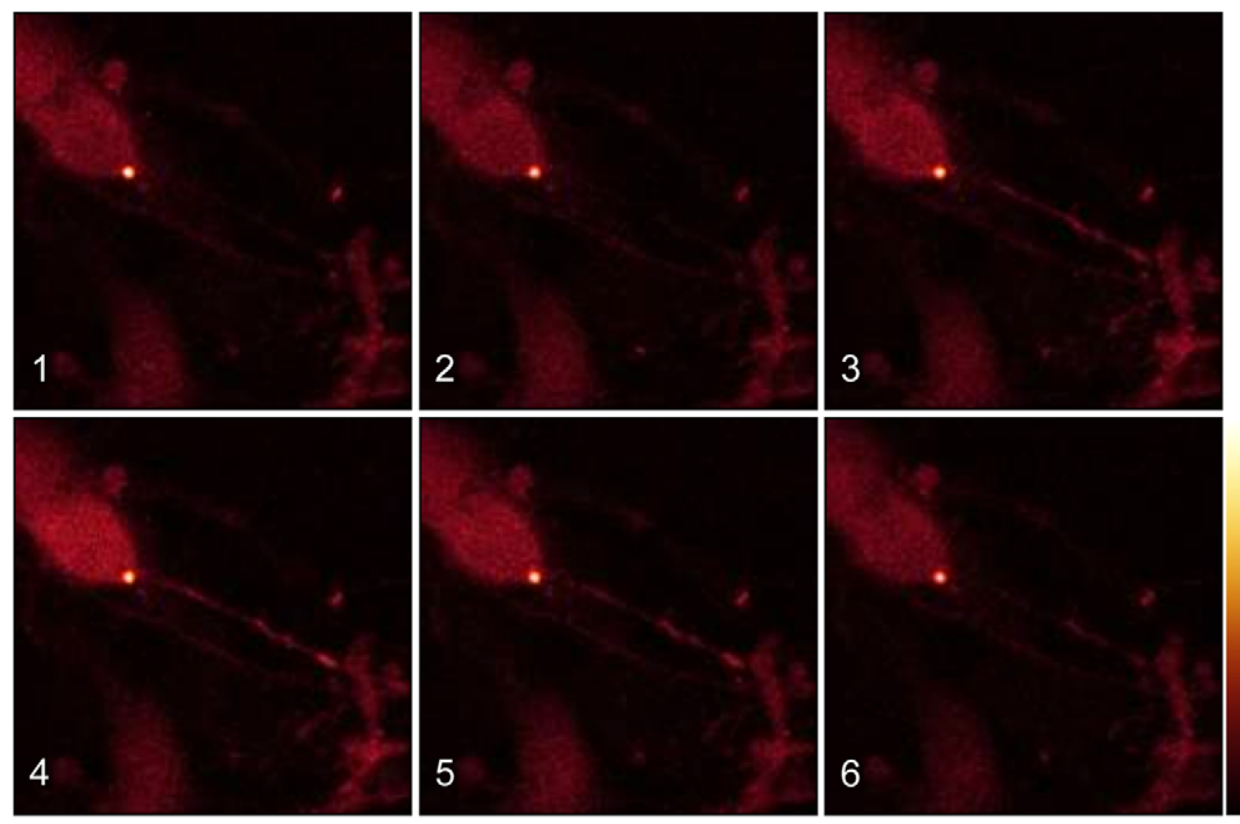

High $\mathrm{Ca}^{++}$

C

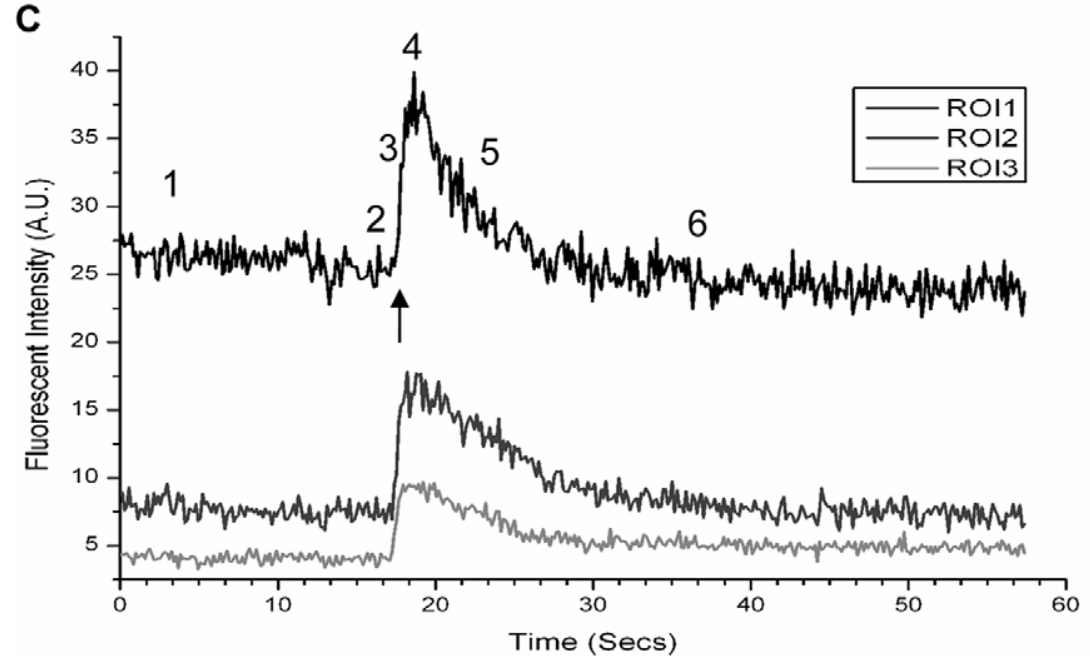

Figure 6. Mechanostimulation of DRG neurons in vitro. The figure shows a representative neuron loaded with Fluo-4 responding to a mechanical stimulus. A) Shows the Fluo-4 fluorescence and DiC image of a DRG neuron. The glass probe is visible in the DiC image, at the moment 
of contact with a neurite (arrow), which projects from the cell body. B) Shows the Fluo-4 fluorescence in pseudo-colour, associated with different time points during the recording. C) The graph shows the recorded fluorescence intensity of different region of interests (ROIs), visible in A. The arrow indicates the time point when the cell was stimulated; cardinal numbers refer to the time points which the images in B are associated to Scale bar is $10 \mu \mathrm{m}$.

doi:10.1371/journal.pone.0040079.g006

Since the molecular identity of mechano-transducers in DRG neurons is currently unknown $[60,61]$ we could not test whether they are also partitioned into lipid rafts, and thus it is unknown whether they would be affected functional by our lipid raft depletion methods. In addition, the lack of a valid positive control for mechano-stimulation does not rule out the possibility that the decrease in responsiveness of neurons, upon raft depletion, may be due to pleiotropic effects of the raft depleting agents, rather than a direct effect on the propagation of the depolarisation. Because of these reasons we have investigated mechano-stimulation of the cell bodies directly, a method of stimulation which does not involve propagation of action potentials through axons. We found that raft disruption did not alter cell responsiveness (\% of responsive cells; $\mathrm{CTR}=60.6 \%, \mathrm{n}=33 ; 50 \mu \mathrm{M}$ CHOL $=61.1 \%, \mathrm{n}=18 ; 50 \mu \mathrm{M}$ $7 \mathrm{KC}=63.6 \%, \mathrm{n}=33 ; 10 \mathrm{mM} \mathrm{M} \beta \mathrm{CD}=68.4 \%, \mathrm{n}=38 . \mathrm{p}>0.5 \mathrm{vs}$. CTR. Fisher's exact test. Table 2). In our hands, direct stimulation of the cell bodies, demonstrates that both mechano-transducers and/or other calcium channels potentially involved in calcium influx, are not affected by raft disruption. This demonstrates that, upon raft depletion, the mechano-transduction mechanism and output measurement are not impaired. We also found that, in the presence of TTX, 15 minutes incubation of small-diameter DRG neurons in $22.7 \mathrm{mM} \mathrm{M} \beta \mathrm{CD}$, did not cause any obvious difference to the amplitude of sodium current densities by patch clamp recording $(31.5+/-18.6 \mathrm{pA} / \mathrm{pF}(\mathrm{CTR})$ vs $28.5+/-15.7 \mathrm{pA} / \mathrm{pF}$ $(22.7 \mathrm{mM} \mathrm{M} \beta \mathrm{CD}))$. This is clearly in agreement with the fact that $\mathrm{Na}_{\mathrm{V}} 1.8$ does not reside in lipid rafts in cell soma (Figure 3A), thus its function in cell soma is not affected by lipid rafts disruption.

\section{Lipid raft disruption negatively affects the propagation of chemically induced depolarisations in DRG neurons in vitro}

We further investigated action potential propagation along the axons of DRG neurons in control and raft depleted conditions by exploiting the properties of Campenot chambers, which allow a compartmentalisation of different parts of the neurons.

Table 1. Axonal mechano-stimulation.

\begin{tabular}{llll}
\hline Treatment & $\mathbf{n}$ & Responsive & \% Responsive neuron \\
\hline CTR & 55 & 28 & 50.9 \\
$\mathrm{Ca}^{++}$-free & 8 & 0 & 0 \\
$\mathrm{Na}^{+}$-free & 15 & 0 & 0 \\
Lidocaine $500 \mu \mathrm{M}$ & 13 & 0 & $0 *$ \\
TTX $250 \mathrm{nM}$ & 8 & 4 & 50.0 \\
CHOL $50 \mu \mathrm{M}$ & 24 & 13 & 54.2 \\
$7 \mathrm{KC} 50 \mu \mathrm{M}$ & 36 & 10 & $27.8 *$ \\
$\mathrm{M} \beta C D ~ 10 \mathrm{mM}$ & 36 & 10 & $27.8 *$ \\
\hline
\end{tabular}

Effect of different compounds and lipid raft disruption on cell body responsiveness, upon axonal stimulation. Table summarises the results of axonal mechano-stimulation of DRG neurons in vitro. Percentages of neuronal cell bodies responsive to mechanical stimulation of the axon, in the different conditions, are listed. ${ }^{*}=p<0.05$ vs. CTR. Fisher's exact test.

doi:10.1371/journal.pone.0040079.t001
We first developed a culture system where DRG neurons can be functionally segregated in different compartments. We used

Table 2. Somal mechano-stimulation.

\begin{tabular}{lccl}
\hline Treatment & $\mathbf{n}$ & Responsive & \% Responsive neuron \\
\hline CTR & 33 & 20 & 60.6 \\
CHOL $50 \mu \mathrm{M}$ & 18 & 11 & 61.1 \\
7KC $50 \mu \mathrm{M}$ & 33 & 21 & 63.6 \\
M $\beta$ CD 10mM & 38 & 26 & 68.4 \\
\hline $\begin{array}{l}\text { Effect of lipid raft disruption on cell responsiveness, upon somal stimulation } \\
\text { Table summarises the results of somal mechano-stimulation of DRG neurons in } \\
\text { vitro. Percentages of neuronal cell bodies responsive to mechanical stimulation } \\
\text { of the soma, in the different conditions, are listed. p > 0.5 vs. CTR. Fisher's exact } \\
\text { test. } \\
\text { doi:10.1371/journal.pone.0040079.t002 }\end{array}$
\end{tabular}

a Campenot chamber with three separate compartments, so that DRG neurons could be spatially separated into, 1) cell bodies (contained in the "soma chamber"), 2) proximal neurites (contained in the "proximal neurite chamber"), and 3) distal neurites (contained in the "distal neurite chamber") in the culture system (Figure 8A).

To study the propagation of depolarisations, we induced action potentials at the neurite terminals in the "distal neurite chamber" by exposing the DRG nerve terminals to a cocktail of chemicals (10 $\mu \mathrm{M}$ Capsaicin, $300 \mu \mathrm{M}$ ATP, $10 \mu \mathrm{M}$ Bradykinin; referred to subsequently as $\mathrm{CAB}$ ) and monitored calcium influx at the level of the cell bodies.

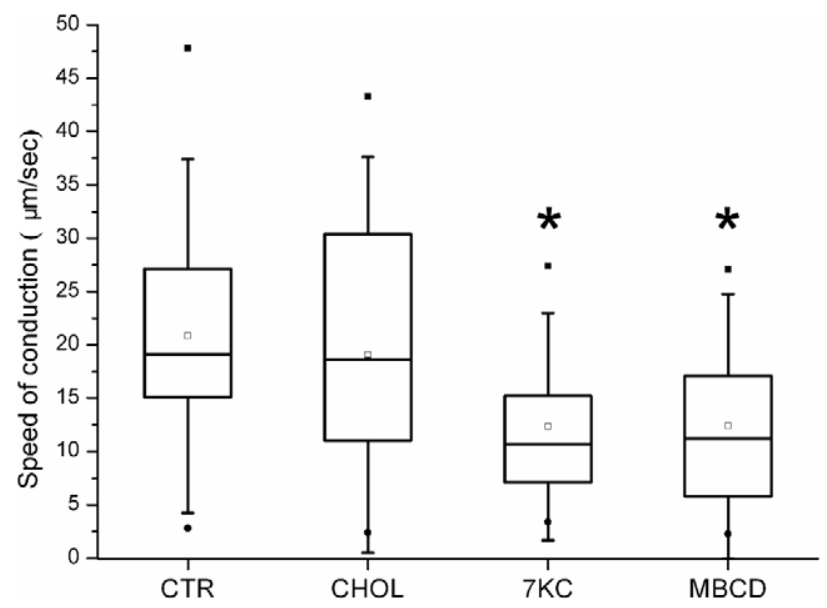

Figure 7. Effect of lipid raft depletion on the speed of propagation of Fluo-4 signals upon mechano-stimulation of the neurites. Box plot show that upon $7 K C$ and $M \beta C D$ treatments the speed of propagation (expressed in $\mu \mathrm{m} / \mathrm{sec}$ ) of the mechanicallyevoked depolarisation is lower, compared to Control (CTR)- and Cholesterol (CHOL)-treated cells. ${ }^{*}=p<0.05$ vs. CTR. Mann-Whitney U Test.

doi:10.1371/journal.pone.0040079.g007 
A

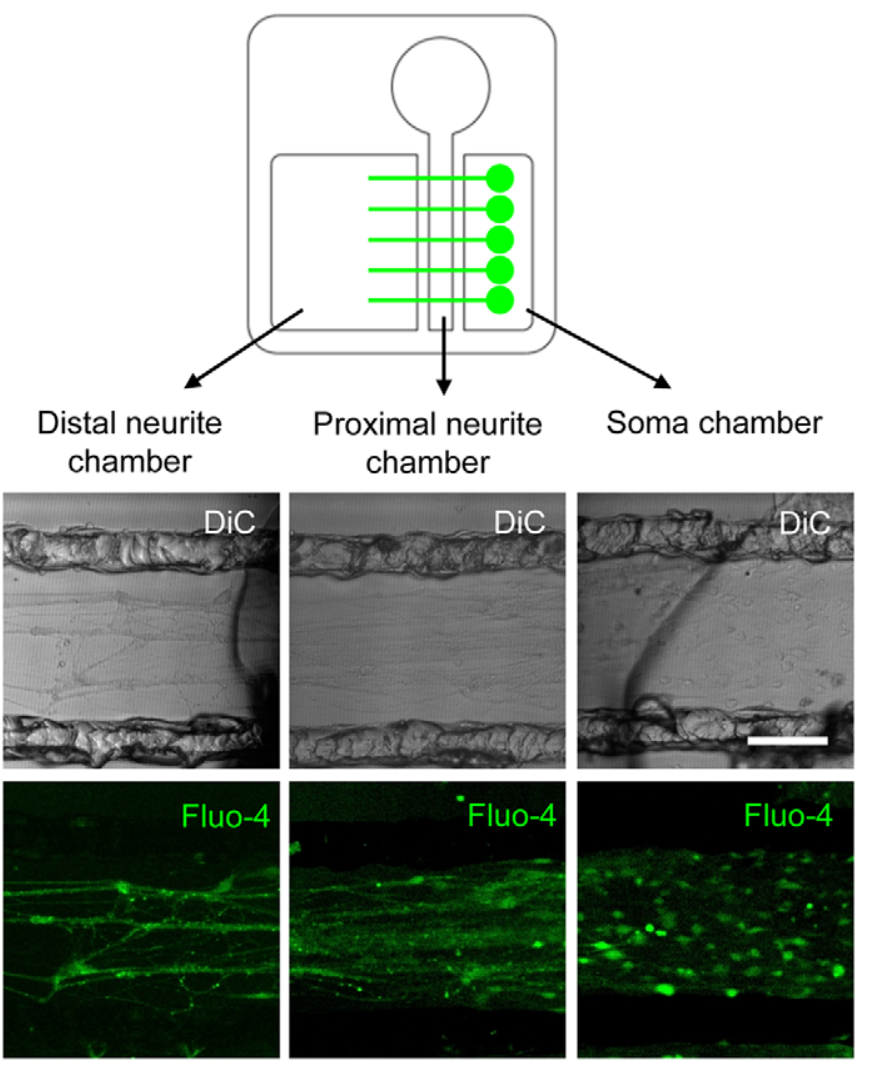

B

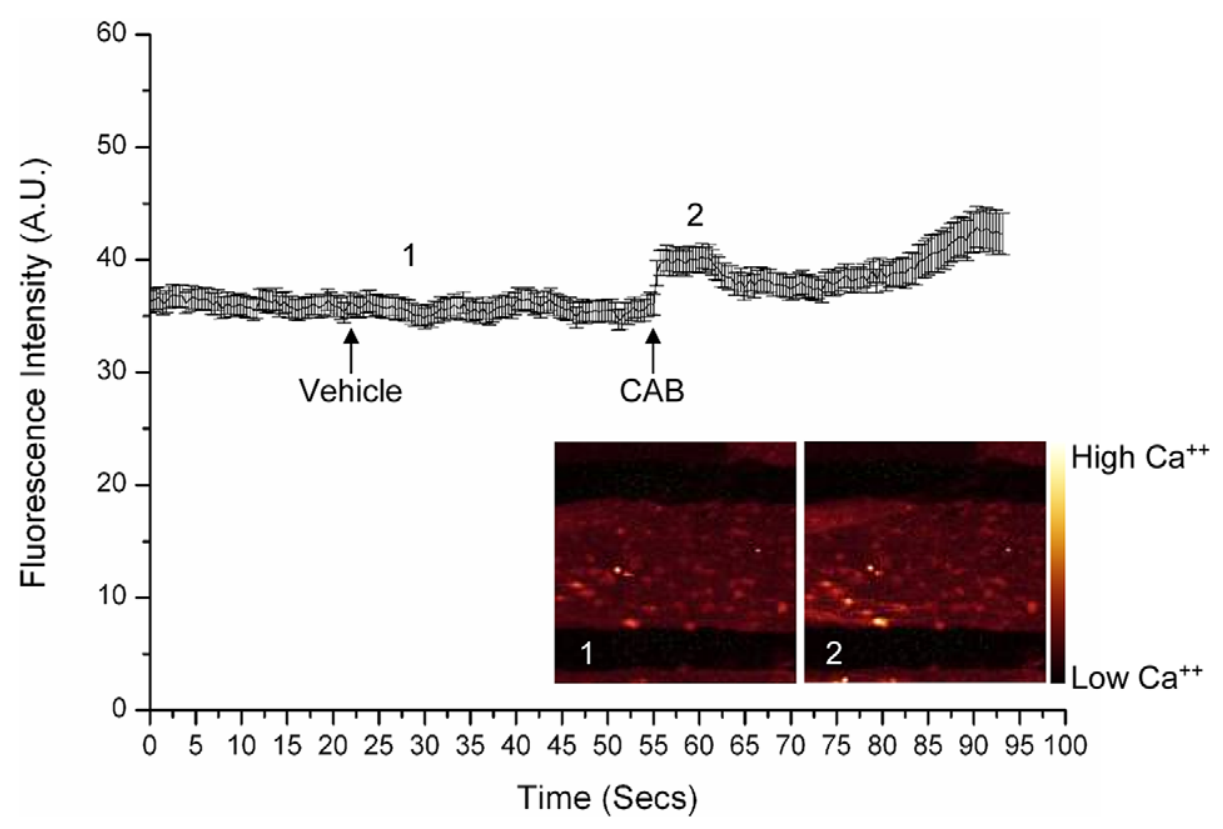

Figure 8. Chemical stimulation of DRG neurons: axonal stimulation and soma recording. The figure shows the effect, at the level of the cell bodies, of axonal chemical stimulation. A) Shows the schematic representation of the Campenot chamber set-up with the Fluo-4 fluorescence and DiC image of the cell bodies (Soma chamber) and neurites projecting to the "Distal neurite" chamber, through the "Proximal neurite" chamber. B) The graph shows the recorded fluorescence intensity of different cell bodies visible in A (Soma chamber). Each data point is the mean fluorescence intensity \pm SEM of different cell bodies $(n=58)$. Images in pseudo-colour represent the "Soma chamber" Fluo-4 fluorescence. The arrows indicate the time points when Vehicle and the Capsaicin, ATP, Bradykinin (CAB) cocktail have been applied; cardinal numbers refer to the time points depicted by the pseudo-colour images. Scale bar is $100 \mu \mathrm{m}$. doi:10.1371/journal.pone.0040079.g008 
We found that axonal stimulation by CAB carried out in the "distal neurite chamber" was able to elicit a calcium influx that traveled through the "proximal neurite chamber" and invaded the cell bodies in the "soma chamber" (Figure 8B, time point 2). Application of vehicle did not elicit any response (Figure 8B, time point 1). We then investigated the nature of the propagating depolarisation by substituting $\mathrm{NaCl}$ in the "proximal neurite chamber" with equimolar choline chloride. When CAB was applied to the "distal neurite chamber", in the absence of sodium ions in the "proximal neurite chamber", we found that no cells responded with an increase of fluorescence, compared to control cells (Table 3). These data clearly indicate that the presence of sodium ions, in the middle part of the neurites, is required for the propagation of an action potential towards the cell bodies. We have also investigated the contribution of TTX-r currents in the propagation of action potentials. For this purpose we added $250 \mathrm{nM}$ TTX to the "proximal neurite chamber" only. This concentration is known to completely block all TTX-s channels. $\mathrm{Na}_{\mathrm{V}} 1.8$, being TTX-r, is not blocked at this concentration $[3,5,9,62]$. In this condition, the TTX-s channels in the "distal axonal compartment" (where stimulation is carried out) and in the "soma compartment" are not blocked. We found that the blockade of TTX-s currents, in the middle regions of axons, did not impair action potential propagation. In fact, compared to the CTR condition, the same number of cells responded to chemical stimulation (mean percentage of responsive neurons in TTX treated samples, expressed as \% of CTR $\pm \mathrm{SEM}=80.3 \pm 8.9$, $\mathrm{n}=3 ; \mathrm{p}=0.15$, Student's unpaired two-tailed $t$-test; Table 3$)$. This result shows that the majority of sodium currents encoding the propagation of the action potential in the middle parts of the axons are indeed mediated by TTX-r VGSCs.

Having demonstrated that action potential propagation was mostly mediated by TTX-r currents (e.g. $\mathrm{Na}_{\mathrm{V}} \mathrm{l}$.8) in this set-up, we investigated the effect of lipid raft disruption and $\mathrm{Na}_{\mathrm{V}} 1.8$ shift to soluble fractions, on the propagation of action potentials. For this purpose, we disrupted lipid rafts with $50 \mu \mathrm{M} 7 \mathrm{KC}$ or $10 \mathrm{mM}$ $\mathrm{M} \beta \mathrm{CD}$ in the "proximal neurite chamber" only and applied CAB to the axonal terminals "distal neurite chamber" and recorded fluorescence intensity at the level of the cell body "soma chamber". Control cells were either left untreated or treated with $50 \mu \mathrm{M}$ cholesterol (CHOL). Upon CAB application we have quantified the number of cells responsive to the chemical

Table 3. Chemical stimulation.

\begin{tabular}{ll}
\hline CTR Treatment & $\mathrm{Na}^{+}$-free condition \\
$100.0 \%$ & $0.0 \%$ \\
CTR Treatment & $\mathrm{TTX}$ Treatment \\
$100.0 \%$ & $80.3 \pm 8.9 \%$ \\
CTR Treatment & $\mathrm{CHOL}$ Treatment \\
$100.0 \%$ & $103.0 \pm 33.6 \%$ \\
CTR Treatment & $7 \mathrm{KC}$ Treatment \\
$100.0 \%$ & $36.1 \pm 13.2 \% *$ \\
CTR Treatment & $\mathrm{M} \beta \mathrm{CD}$ Treatment \\
$100.0 \%$ & $36.6 \pm 10.0 \% *$ \\
\hline
\end{tabular}

Effect of different compounds and lipid raft disruption on cell responsiveness, upon chemical stimulation. Table shows the percentage of neurons responding to axonal chemical stimulation after the different treatments. Data are presented as means of responsive neurons expressed as \% of CTR \pm SEM. * $=\mathrm{p}<0.05$ vs. CTR, Mann-Whitney test.

doi:10.1371/journal.pone.0040079.t003 stimulation and found that, upon raft depletion, $7 \mathrm{KC}$ and $\mathrm{M} \beta \mathrm{CD}$ treatments significantly decreased the percentage of cells responding to the chemical stimulation. On the other hand, cholesterol treatment did not cause any effect on action potential conduction (mean percentage of responsive neurons, expressed as \% of CTR \pm SEM; CHOL $=103.0 \pm 33.6, \mathrm{n}=3 ; 7 \mathrm{KC}=36.1 \pm 13.2 *, \mathrm{n}=5$; $\mathrm{M} \beta \mathrm{CD}=36.6 \pm 10.0 *, \mathrm{n}=4 ; *=\mathrm{p}<0.01$ vs CTR, Student's unpaired two-tailed $t$-test. Table 3 ).

\section{Discussion}

$\mathrm{Na}_{\mathrm{V}} 1.8$ is a major determinant of nociceptor excitability, being responsible for the generation of action potentials in these neurons. In our hands TTX-r channels proved to be sufficient for the propagation of depolarization through the axons towards the cell bodies. The involvement of other TTX-r channels (e.g. Na 1.5, $\mathrm{Na}_{\mathrm{V}} 1.9$ ) can not be ruled out. Nevertheless, $\mathrm{Na}_{\mathrm{V}} 1.5$ is not expressed in nociceptors and $\mathrm{Na}_{\mathrm{V}} 1.9$ is characterised by slow activation-deactivation kinetcs $[2,6,63]$, hence is not suitable for action potential conduction. Our data, combined with current knowledge of TTX-r channels, suggest that $\mathrm{Na}_{\mathrm{V}} 1.8$ is the most likely candidate involved in the propagation of depolarizations in nociceptors.

Previous studies have characterised its electrophysiological features and unveiled mechanisms regulating its trafficking. Nevertheless, a comprehensive description of $\mathrm{Na}_{\mathrm{V}} 1.8$ localisation in nociceptors is still unavailable. A more detailed knowledge of $\mathrm{Na}_{\mathrm{V}} 1.8$ sub-cellular localisation in nociceptors may lead to a deeper understanding of the mechanism of excitability in nociceptors.

In the present report, we have demonstrated that $\mathrm{Na}_{\mathrm{V}} 1.8$ is localised in clusters along the axons of unmyelinated neurons in vitro and in vivo and resides within lipid rafts. The meaning of the clustered distribution is unknown at present. The spatial localisation of ion channels is of paramount importance in shaping the electrical excitability of neuronal cells [64]. The clustered appearance of $\mathrm{Na}_{\mathrm{V}} 1.8$ could have a functional role in terms of action potential propagation along the axons; where this channel is expressed. One possibility is that, in unmyelinated fibres, $\mathrm{Na}_{\mathrm{V}} 1.8$ clusters represent sites on the membrane where action potentials can be actively generated. It is tempting to hypothesise an electrical conduction mechanism whereby, in the portion of membrane lacking $\mathrm{Na}_{\mathrm{V}} 1.8$, the electrical signal would spread in a manner dependent on passive cable properties, but, just before dissipating, it could be re-generated at the sites of Nav1.8 clustering. The close vicinity of the clusters we have found in our experiments (5-10 $\mu \mathrm{m}$, Figure 1C) may represent a distance just short enough for the passively conducted depolarisation not to dissipate and to be regenerated and further propagated from cluster to cluster, via recruitment of $\mathrm{Na}_{\mathrm{V}}$ 1.8. Interestingly, classic studies support a mechanism of action potential conduction in unmyelinated fibres similar to this hypothesis. Upon demyelination, sodium channels redistribute along the unmyelinated region $[65,66,67]$ and electrophysiological analysis have reported that, in demyelinated axons, action potential conduction is restored before re-myelination occurs. In this condition, conduction was found to be discontinuous and proceeded via "new foci of inward membrane current", hypothesised to be clusters of VGSGs [68]. The biological meaning of clusters could also be attributed to the fact that clusters of $\mathrm{Na}_{\mathrm{V}} 1.8$ increase its local concentration. It has been demonstrated that a high concentration of VGSCs is necessary for efficient action potential generation, as in the case of nodes of Ranvier, where VGSCs are highly concentrated $\left(>1200 / \mu \mathrm{m}^{2}\right)$ [69], and in the axonal initial segment [70]. 
Another example of clusters of VGSCis at high density has been reported by Engel and Jonas. Remarkably, this study demonstrated that, in the hippocampal mossy fibre pathway, VGSCs are present at high concentration in the en passant boutons along the unmyelinated fibres. The authors conclude that the high density of VGSGs is needed to amplify action potentials at the pre-synaptic sites, and boost neurotransmitter release. Also, by computational modelling, it has been predicted that the clusters of VGSCs at the boutons along the axons influence the reliability and velocity of action potential propagation [71]. We have also demonstrated that mechanical and chemical stimuli are able to elicit calcium influx at the level of the cell bodies following axonal stimulation. Furthermore, cell body responsiveness depends on the presence of sodium ions in the media, it is blocked by lidocaine (a sodium channel blocker) and is unaffected by TTX (which binds to TTX sensitive channels but not to $\mathrm{Na}_{\mathrm{V}} 1.8$ ). These results points at $\mathrm{Na}_{\mathrm{V}} 1.8$ as the key mediator of the propagation of the mechanically- and chemically-evoked depolarisation. Further investigation with electrophysiological techniques could clarify the biological significance of $\mathrm{Na}_{V} 1.8$ sub-cellular distribution in terms of action potential propagation in our experimental set-up and in vivo. In summary, since neuronal excitability is dependent on many factors, including ion channel sub-cellular localisations and local densities, $\mathrm{Na}_{\mathrm{V}} 1.8$ clusters may be at the base of action potential generation and conduction, and be important to shape the excitability of unmyelinated axons of nociceptors.

In the present report we also show that $\mathrm{Na}_{\mathrm{V}} 1.8$ resides in lipid rafts in the axons of unmyelinated fibres. We do not have information about the sorting signals that drive $\mathrm{Na}_{V} 1.8$ to membrane rafts. Previous reports demonstrated that $\mathrm{Na}_{\mathrm{V}} 1.8$ must bind to chaperon protein $\mathrm{p} 11$ to be efficiently translocated into the neuronal membrane [24]. Also, pll itself has been found to partition in lipid rafts $[72,73,74]$. It could be hypothesised that $\mathrm{pl} 1$ act as a raft-sorting factor for $\mathrm{Na}_{\mathrm{V}} 1.8$. Other chaperon proteins such as $\operatorname{Pdzd} 2$ may also be responsible for $\mathrm{Na}_{\mathrm{V}} 1.8$ clustering in lipid rafts [75]. In addition, sodium channel sub-unit $\beta 1$ has been shown to partition into lipid raft and to act as a cell adhesion molecule. Given these data it would interesting to explore the possibility that sub-unit $\beta 1$ is involved in $\mathrm{Na}_{\mathrm{V}} 1.8$ targeting and clustering in rafts [76].

It should also be noted that a minority of $\mathrm{Na}_{\mathrm{v}} 1.8$ clusters colocalised with Gaveolin-2, and there are two potential Caveolin binding sites within the $\mathrm{Na}_{\mathrm{v}} 1.8 \alpha$-subunit.

Additional proof for $\mathrm{Na}_{\mathrm{V}} 1.8$ trafficking to lipid rafts came from the evidence that, in our hands, the disruption of membrane rafts correlates with $\mathrm{Na}_{\mathrm{V}} 1.8$ shifting to the non-raft portion of the membrane. We employed M $\mathrm{MCD}$ and $7 \mathrm{KC}$ to negatively affect raft integrity. M $\beta C D$ represents the 'gold standard' for experimental cholesterol depletion from membrane. Indeed lipid raft integrity relies on the presence of cholesterol in the membrane; M $\beta C D$ mediated cholesterol efflux determines disruption of lipid rafts $[20,77,78,79]$. $7 \mathrm{KC}$, on the other hand, modulates raft properties, and their ability to resist non-ionic detergent lysis, by decreasing the degree of order of the lipid phase [25]. 7KC differs from cholesterol only for a ketone group which protrudes perpendicularly from the sterol plane. The ketone group limits the depth of $7 \mathrm{KC}$ insertion into the membrane and its interaction with phospholipids acyl chains. Importantly, the alignment of the sterol ring of $7 \mathrm{KC}$ with trans-configured saturated acyl chains of sphingoglycolipids is impaired and this leads to decreased formation of ordered membrane domains [46]. Importantly, lipid raft depletion leads to a $\mathrm{Na}_{\mathrm{V}} 1.8$ shift to the soluble portion of the membrane and it correlates with impaired neuronal excitability in DRG neurons. Lipid rafts play a role in protein clustering on the membrane $[28,29]$. We initially hypothesised that lipid raft integrity was necessary for the maintenance of $\mathrm{Na}_{\mathrm{V}} 1.8$ clusters and efficient neuronal excitability. In contrast, $\mathrm{M} \beta \mathrm{CD}$ and $7 \mathrm{KC}$ did not change its distribution on the membrane, although there is a possibility that the distances between each $\mathrm{Na}_{\mathrm{V}} 1.8$ molecule in the clusters were widened by lipid raft disruption, but this could not be detected by the current method. Other approaches, such as electron microscopy or FRET assay, may help to reveal the changes of $\mathrm{Na}_{\mathrm{V}} 1.8$ location beyond the detection level of confocal microscopy. Also, it is worth underlining that we have analysed $\mathrm{Na}_{\mathrm{V}} 1.8$ shortly after raft depletion. It is undisputed that ion channels are tethered to the cytoskeletal protein $[64,80]$. If raft had an influence on channel's clustering it could be hypothesised that the network linking $\mathrm{Na}_{\mathrm{V}} 1.8$ to the cytoskeleton may mask this effect upon an acute raft depletion and short term observation. An alternative hypothesis may potentially explain the failure of the propagation of the depolarisations mediated by $\mathrm{Na}_{\mathrm{V}} 1.8$. There is a constantly growing body of evidence which focuses on how lipid rafts directly alter the electrophysiological properties of ion channels (reviewed in [19]). Rafts are characterised by a liquid ordered phase, with different lateral pressures, viscosity and bylayer thickness, compared to non-raft regions of the membrane. These parameters can influence protein properties by modulating, for example, kinetics of transition between different conformational states (e.g. the process open-closed-inactivated in VGSCs) $[77,81,82,83,84,85]$. It has been predicted, for example, that $\mathrm{Na}_{\mathrm{V}} 1.6$ channels conformational equilibria would differ between "bulk" non raft membranes and lipid rafts [86]. So far all electrophysiological recordings for $\mathrm{Na}_{\mathrm{V}} 1.8$ have been made at the cell soma level where $\mathrm{Na}_{\mathrm{V}} 1.8$ does not colocalise with lipid rafts. On the other hand, patch clamping of unmyelinated axonal membranes has not yet been achieved. It is, therefore, plausible that the properties (namely activation threshold) of clustered $\mathrm{Na}_{\mathrm{V}} 1.8$ in lipid rafts may be different from the channels reside in the cell soma membrane. Thus, it could be argued that M $\beta \mathrm{CD}$ and $7 \mathrm{KC}$-mediated raft disruption alters the biophysical property of membrane rafts, which in turn affect $\mathrm{Na}_{V} 1.8$ electrophysiological characteristics, and ultimately cell excitability.

Lipid rafts also modulate cell signalling, by segregating or facilitating the interaction of certain molecules [36,87,88,89]. A potential way rafts could influence action potential propagation is by indirectly influencing $\mathrm{Na}_{\mathrm{V}} 1.8$ properties. $\mathrm{Na}_{\mathrm{V}} 1.8$ currents are modulated by NGF, which binds to TrkA, and intracellularly by PKA and PKCe [90]. In neuronal cells, PKC and TrkA have been reported to translocate into lipid rafts upon activation and that raft integrity is required for intracellular signalling [91,92]. In our model, a plausible hypothesis could be that raft depletion alters the signalling between TrkA, PKC $\varepsilon$ and $\mathrm{Na}_{\mathrm{V}} 1.8$ resulting in modified properties of $\mathrm{Na}_{\mathrm{V}}$ 1.8. Lipid rafts have also been shown to regulate endocytosis of membrane proteins [20]. One potential explanation for failure of action potential conduction in raft-depleted samples could be that, in the absence of rafts, $\mathrm{Na}_{\mathrm{V}} 1.8$ is recruited into endocytotic pathways. This would lead to a reduction of TTX-r currents, which will impair impulse propagation along the axons.

We have demonstrated that TTX-s channels (e.g. Nav1.7 in nociceptors) do not substantially contribute to action potential propagation in our system (Table 3). Nevertheless, it may be hypothesised that $\mathrm{Na}_{\mathrm{V}} 1.7$ also partitions into lipid rafts and may have an indirect effect on $\mathrm{Na}_{\mathrm{V}} 1.8$-mediated action potential propagation. If raft depletion altered $\mathrm{Na}_{\mathrm{V}} 1.7$ properties, we could speculate that a defective boost of ramp currents (mediated by this channel [93]) may impair $\mathrm{Na}_{\mathrm{V}} 1.8$ recruitment, due to its high threshold of activation [94]. $\mathrm{Na}_{\mathrm{V}} 1.9$, the other TTX-r VGSC expressed in sensory neurons, is not involved in action potential 
generation because of its electrophysiological properties, and instead contributes to set the resting membrane potential [6]. If raft disruption altered $\mathrm{Na}_{\mathrm{V}} 1.9$ gating properties, a change in resting membrane potential could affect $\mathrm{Na}_{\mathrm{V}} 1.8$ availability to fire action potentials. These examples could be extended to other classes of proteins that contribute to membrane excitability, like $\mathrm{Na}^{+} / \mathrm{K}^{+}$ATPase and leaky potassium channels. Thus, we highlight the potential importance to study different classes of proteins specifically localised in lipid rafts of nociceptors.

In conclusion, we have found that $\mathrm{Na}_{\mathrm{V}} 1.8$ resides in lipid rafts along the axons of DRG neurons in vitro and in vivo. Furthermore, the depletion of lipid rafts leads to $\mathrm{Na}_{\mathrm{V}} 1.8$ being shifted to the nonraft portion of the membrane and it correlates with impaired cell excitability. We conclude that the effect of lipid rafts on cell excitability represents a novel aspect to be considered in the efforts aiming to understand the fundamental properties of nociceptors and neuronal cells in general.

\section{Supporting Information}

Figure $\mathrm{S} 1 \mathrm{Na} 1.8$ sub-cellular distribution in largediameter neurons in vitro. In large-diameter neurons, identified by morphology (A, right panel) and by the immunoreactivity for $\mathrm{NF} 200$ (B, right panel), $\mathrm{Na}_{\mathrm{V}} 1.8$ is evenly distributed, or associated in large patches, along the neurites (A, B; arrowheads). $\mathrm{Na}_{\mathrm{V}} 1.8$ is also enriched in the cell somas (A, asterisk). Phase contrast images in A show the overall morphology of the neurons (neurites and cell bodies) with $\mathrm{Na}_{\mathrm{V}} 1.8$ immunoreactivity superimposed. Scale bars are $20 \mu \mathrm{m}$.

(DOCX)

Figure S2 Nav1.8-DsRed2 does not display green fluorescent protein properties. We transfected ND7-23 cells with $\mathrm{Na}_{\mathrm{V}}$ 1.8-DsRed2 or green fluorescent protein (GFP) and imaged the cells 24 hours after transfection (Method S2). The image shows that the filter set and acquisition properties (Green channel) is suited to visualise the GFP (acting as positive control). When Nav1.8-DsRed2 is imaged with these settings it does not show any green fluorescence. On the contrary, $\mathrm{Na}_{\mathrm{V}} 1.8-\mathrm{D}$ sRed2 associated fluorescence is only visualised when the construct is imaged with settings suitable to collect red fluorescence (Red channel). ND7-23 were imaged at low (40x objective) and high (100x objective) magnification. It is worth noting that in this cell type GFP construct diffuses throughout the cell while $\mathrm{Na}_{\mathrm{V}} 1.8-\mathrm{DsRed} 2$ is excluded from the nucleus. Scale bars are $20 \mu \mathrm{m}$.

(DOCX)

Figure S3 Nav1.8 preferentially colocalises with Flotillin1-Dronpa. DRG neurons were transfected with plasmids encoding fluorescent constructs Flotillin1-Dronpa and Caveolin2Dronpa, markers for planar and caveola type lipid rafts respectively. Endogenous $\mathrm{Na}_{\mathrm{V}} 1.8$ was immuno-localised after 2 DIV. A, shows a representative neuron expressing Flotillin1Dronpa. We found that Flotillin-1-Dronpa is localised both in the soma and along the neurites of DRG neurons. This construct was evenly distributed, with brighter puncta of fluorescence along the axons (arrowheads). Interestingly, when we correlated the fluorescence of Flotillin-1-Dronpa to the localisation of endogenous $\mathrm{Na}_{\mathrm{V}} 1.8$, we found that $\mathrm{Na}_{\mathrm{V}} 1.8$ clusters showed colocalisation with the brighter spots of Flotillin-1-Dronpa along the axons (arrows). B, shows a representative neuron expressing Caveolin2-Dronpa. Caveolin-2-Dronpa showed a distinct clustered organisation along the neurites (arrowheads). In neurons with a clustered distribution of Caveolin-2-Dronpa, we found that few $\mathrm{Na}_{\mathrm{V}} 1.8$ clusters were associated with Caveolin-2-Dronpa puncta, with the majority being excluded from it. Scale bars are $20 \mu \mathrm{m}$.

(DOCX)

Figure S4 7KG and MBCD effect on DRG neurons detected by using lipid phase sensitive probe di-4ANEPPDHQ. We employed imaging techniques to monitor $7 \mathrm{KC}$ and $\mathrm{M} \beta \mathrm{CD}$ mediated lipid rafts disruption. We exploited the remarkable feature of fluorescent dye di-4-ANEPPDHQ to act as a sensor for the membrane lipid phase [43]. It displays a blue-shift of the emission spectrum in the liquid ordered phase (raft-like) compared to liquid disordered phase (non raft) [44]. Since M $\beta C D$ and $7 \mathrm{KC}$ disrupt lipid rafts we hypothesised that the emission of di-4-ANEPPDHQ would be red-shifted compared to controls samples, because of a reduced liquid ordered phase (reflecting a decreased amount of liquid ordered lipid raft microdomains). We treated cells with $50 \mu \mathrm{M} 7 \mathrm{KC}$ and $10 \mathrm{mM} \mathrm{M} \beta \mathrm{CD}$ to disrupt lipid rafts; Control cells were either treated with $50 \mu \mathrm{M}$ cholesterol (CHOL) or left untreated (CTR). To determine the effect of the compounds on the lipid phase we constructed the emission spectra of di-4-ANEPPDHQ by performing a $\lambda$ scan. The graph shows the normalised emission spectra of the di-4-ANEPPDHQ bound to DRG neurons. The spectra are constructed by reading fluorescence intensity from $510 \mathrm{~nm}$ to $690 \mathrm{~nm}$ (each data point is presented as the mean fluorescence intensity \pm SEM). CTR and CHOL treated samples show completely overlapping spectra, suggesting that CHOL treatmeant does not alter the phase of the membrane. On the contrary, both $7 \mathrm{KC}$ and M $\mathrm{MCD}$ determine a red-shift of the spectra, compared to GTR and CHOL treated samples (Calculated emission maxima, presented as mean emission maxima \pm SEM: CTR $=590 \pm 0 \mathrm{~nm} ; \quad$ CHOL $=590 \pm 0 \mathrm{~nm}$; $7 \mathrm{KC}=596 \pm 1.8 \mathrm{~nm} \quad * \quad \quad$ *; $\quad \mathrm{M} \beta \mathrm{CD}=596 \pm 1.6 \mathrm{~nm} \quad * \quad \quad \quad$; $*=p<0.01$ vs CTR, ${ }^{*}=p<0.01$ vs CHOL. One-way ANOVA, followed by Tukey's post-hoc tests; $n=11$ ). This result clearly indicates that both $7 \mathrm{KC}$ and $\mathrm{M} \beta \mathrm{CD}$, alter the lipid phase of the neurons, shifting it to a less ordered phase, consistent with raft disruption.

(DOCX)

Figure S5 Lipid raft disruption does not alter $\mathrm{Na}_{\mathrm{V}} 1.8-$ cluster distribution. Representative images demonstrating endogenous $\mathrm{Na}_{\mathrm{V}} 1.8$ immuno-localised in DRG neurons after 2 DIV upon raft disruption with $7 \mathrm{KC}$ and M $\mathrm{CCD}$. Control cells were either left untreated (CTR) or treated with cholesterol (CHOL). The images show DRG neurons with $\mathrm{Na}_{V} 1.8$ distinct puncta along the neurites (arrows). (DOCX)

Method S1 Di-4-ANEPPDHQ loading and imaging in cultured DRG neurons. (DOCX)

Method S2 ND7-23 culture and transfection. (DOCX)

\section{Acknowledgments}

This work was supported by the Wellcome Trust. AP and KO are members of the Wellcome Trust London Pain Consortium.

\section{Author Contributions}

Conceived and designed the experiments: AP KO. Performed the experiments: AP MDB. Analyzed the data: AP MDB KO. Contributed reagents/materials/analysis tools: AP MDB KO. Wrote the paper: AP MDB KO 


\section{References}

1. Hille B (2001) Ion channels of excitable membranes. Sunderland, Mass.: Sinauer. xviii, $814 \mathrm{p}$.

2. Rook MB, Evers MM, Vos MA, Bierhuizen MF (2012) Biology of cardiac sodium channel Nav1.5 expression. Cardiovasc Res 93: 12-23.

3. Akopian AN, Sivilotti L, Wood JN (1996) A tetrodotoxin-resistant voltage-gated sodium channel expressed by sensory neurons. Nature 379: 257-262.

4. Millan MJ (1999) The induction of pain: an integrative review. Prog Neurobiol 57: $1-164$

5. Renganathan M, Cummins TR, Waxman SG (2001) Contribution of $\mathrm{Na}(\mathrm{v}) 1.8$ sodium channels to action potential electrogenesis in DRG neurons. J Neurophysiol 86: 629-640.

6. Dib-Hajj S, Black JA, Cummins TR, Waxman SG (2002) NaN/Nav1.9: a sodium channel with unique properties. Trends Neurosci 25: 253-259.

7. Matthews EA, Wood JN, Dickenson AH (2006) Na(v) 1.8-null mice show stimulus-dependent deficits in spinal neuronal activity. Mol Pain 2: 5.

8. Jarvis MF, Honore P, Shieh CC, Chapman M, Joshi S, et al. (2007) A-803467, a potent and selective Nav1.8 sodium channel blocker, attenuates neuropathic and inflammatory pain in the rat. Proc Natl Acad Sci U S A 104: 8520-8525.

9. Akopian AN, Souslova V, England S, Okuse K, Ogata N, et al. (1999) The tetrodotoxin-resistant sodium channel SNS has a specialized function in pain pathways. Nat Neurosci 2: 541-548.

10. Waxman SG, Kocsis JD, Stys PK (1995) The axon: structure, function, and pathophysiology. New York: Oxford University Press. xv, 692 p. of plates p.

11. Black JA, Waxman SG (2002) Molecular identities of two tetrodotoxin-resistant sodium channels in corneal axons. Exp Eye Res 75: 193-199.

12. Rush AM, Craner MJ, Kageyama T, Dib-Haji SD, Waxman SG, et al. (2005) Contactin regulates the current density and axonal expression of tetrodotoxinresistant but not tetrodotoxin-sensitive sodium channels in DRG neurons. Eur J Neurosci 22: 39-49.

13. Persson AK, Black JA, Gasser A, Cheng X, Fischer TZ, et al. (2010) Sodiumcalcium exchanger and multiple sodium channel isoforms in intra-epidermal nerve terminals. Mol Pain 6: 84

14. Simons K, Gerl MJ (2010) Revitalizing membrane rafts: new tools and insights. Nat Rev Mol Cell Biol 11: 688-699.

15. Pike LJ (2006) Rafts defined: a report on the Keystone Symposium on Lipid Rafts and Cell Function. J Lipid Res 47: 1597-1598.

16. Coskun U, Simons K (2010) Membrane rafting: from apical sorting to phase segregation. FEBS Lett 584: 1685-1693.

17. Brown DA, Rose JK (1992) Sorting of GPI-anchored proteins to glycolipidenriched membrane subdomains during transport to the apical cell surface. Cell 68: 533-544.

18. London E, Brown DA (2000) Insolubility of lipids in triton X-100: physical origin and relationship to sphingolipid/cholesterol membrane domains (rafts). Biochim Biophys Acta 1508: 182-195.

19. Pristera A, Okuse K (2011) Building Excitable Membranes: Lipid Rafts and Multiple Controls on Trafficking of Electrogenic Molecules. Neuroscientist.

20. Hering H, Lin CC, Sheng M (2003) Lipid rafts in the maintenance of synapses, dendritic spines, and surface AMPA receptor stability. J Neurosci 23: 3262 3271 .

21. Martens JR, Navarro-Polanco R, Coppock EA, Nishiyama A, Parshley L, et al. (2000) Differential targeting of Shaker-like potassium channels to lipid rafts. J Biol Chem 275: 7443-7446.

22. Swanwick RS, Pristera A, Okuse K (2010) The trafficking of $\mathrm{Na}(\mathrm{V}) 1.8$. Neurosci Lett 486: 78-83.

23. Djouhri L, Fang X, Okuse K, Wood JN, Berry CM, et al, (2003) The TTXresistant sodium channel Nav1.8 (SNS/PN3): expression and correlation with membrane properties in rat nociceptive primary afferent neurons. J Physiol 550: $739-752$.

24. Okuse K, Malik-Hall M, Baker MD, Poon WY, Kong H, et al. (2002) Annexin II light chain regulates sensory neuron-specific sodium channel expression. Nature 417: 653-656.

25. Rentero C, Zech T, Ouinn CM, Engelhardt K, Williamson D, et al. (2008) Functional implications of plasma membrane condensation for $\mathrm{T}$ cell activation. PLoS ONE 3: e2262.

26. Basbaum AI, Bautista DM, Scherrer G, Julius D (2009) Cellular and molecular mechanisms of pain. Cell 139: 267-284.

27. Basbaum AI, Woolf CJ (1999) Pain. Curr Biol 9: R429-431

28. Bruses JL, Chauvet N, Rutishauser U (2001) Membrane lipid rafts are necessary for the maintenance of the (alpha)7 nicotinic acetylcholine receptor in somatic spines of ciliary neurons. J Neurosci 21: 504-512.

29. Willmann R, Pun S, Stallmach L, Sadasivam G, Santos AF, et al. (2006) Cholesterol and lipid microdomains stabilize the postsynapse at the neuromuscular junction. EMBO J 25: 4050-4060.

30. Harder T, Scheiffele P, Verkade P, Simons K (1998) Lipid domain structure of the plasma membrane revealed by patching of membrane components. J Cell Biol 141: 929-942.

31. Langhorst MF, Reuter A, Stuermer CA (2005) Scaffolding microdomains and beyond: the function of reggie/flotillin proteins. Cell Mol Life Sci 62: 22282240 .

32. Lang DM, Lommel S, Jung M, Ankerhold R, Petrausch B, et al. (1998) Identification of reggie-1 and reggie-2 as plasmamembrane-associated proteins which cocluster with activated GPI-anchored cell adhesion molecules in noncaveolar micropatches in neurons. J Neurobiol 37: 502-523.

33. Parton RG, Simons K (2007) The multiple faces of caveolae. Nat Rev Mol Cell Biol 8: 185-194

34. Habuchi S, Ando R, Dedecker P, Verheijen W, Mizuno H, et al. (2005) Reversible single-molecule photoswitching in the GFP-like fluorescent protein Dronpa. Proc Natl Acad Sci U S A 102: 9511-9516.

35. Allen JA, Halverson-Tamboli RA, Rasenick MM (2007) Lipid raft microdomains and neurotransmitter signalling. Nat Rev Neurosci 8: 128-140.

36. Golub T, Wacha S, Caroni P (2004) Spatial and temporal control of signaling through lipid rafts. Curr Opin Neurobiol 14: 542-550.

37. Simons K, Ikonen E (1997) Functional rafts in cell membranes. Nature 387: 569-572.

38. Gold MS, Weinreich D, Kim CS, Wang R, Treanor J, et al. (2003) Redistribution of $\mathrm{Na}(\mathrm{V}) 1.8$ in uninjured axons enables neuropathic pain. J Neurosci 23: 158-166.

39. Goldin AL, Barchi RL, Caldwell JH, Hofmann F, Howe JR, et al. (2000) Nomenclature of voltage-gated sodium channels. Neuron 28: 365-368.

40. Schmidt JW, Catterall WA (1987) Palmitylation, sulfation, and glycosylation of the alpha subunit of the sodium channel. Role of post-translational modifications in channel assembly. J Biol Chem 262: 13713-13723.

41. Yu FH, Catterall WA (2003) Overview of the voltage-gated sodium channel family. Genome Biol 4: 207.

42. Morenilla-Palao C, Pertusa M, Meseguer V, Cabedo H, Viana F (2009) Lipid raft segregation modulates TRPM8 channel activity. J Biol Chem 284: 92159224.

43. Alfalah M, Jacob R, Preuss U, Zimmer KP, Naim H, et al. (1999) O-linked glycans mediate apical sorting of human intestinal sucrase-isomaltase through association with lipid rafts. Curr Biol 9: 593-596.

44. Scheiffele P, Peranen J, Simons K (1995) N-glycans as apical sorting signals in epithelial cells. Nature 378: 96-98.

45. Gaus K, Kritharides L, Schmitz G, Boettcher A, Drobnik W, et al. (2004) Apolipoprotein A-1 interaction with plasma membrane lipid rafts controls cholesterol export from macrophages. FASEB J 18: 574-576.

46. Massey JB, Pownall HJ (2005) The polar nature of 7-ketocholesterol determines its location within membrane domains and the kinetics of membrane microsolubilization by apolipoprotein A-I. Biochemistry 44: 10423-10433.

47. Jin L, Millard AC, Wuskell JP, Clark HA, Loew LM (2005) Cholesterol-enriched lipid domains can be visualized by di-4-ANEPPDHQ with linear and nonlinear optics. Biophys J 89: L04-06.

48. Jin L, Millard AC, Wuskell JP, Dong X, Wu D, et al. (2006) Characterization and application of a new optical probe for membrane lipid domains. Biophys J 90: 2563-2575.

49. Tsunozaki M, Bautista DM (2009) Mammalian somatosensory mechanotransduction. Curr Opin Neurobiol 19: 362-369.

50. Kandel ER, Schwartz JH, Jessell TM (2000) Principles of neural science. New York: McGraw-Hill, Health Professions Division. xli, 1414 p.

51. McCarter GC, Reichling DB, Levine JD (1999) Mechanical transduction by rat dorsal root ganglion neurons in vitro. Neurosci Lett 273: 179-182.

52. Cho H, Shin J, Shin CY, Lee SY, Oh U (2002) Mechanosensitive ion channels in cultured sensory neurons of neonatal rats. J Neurosci 22: 1238-1247.

53. Hu J, Lewin GR (2006) Mechanosensitive currents in the neurites of cultured mouse sensory neurones. J Physiol 577: 815-828.

54. Drew LJ, Rugiero F, Cesare P, Gale JE, Abrahamsen B, et al. (2007) Highthreshold mechanosensitive ion channels blocked by a novel conopeptide mediate pressure-evoked pain. PLoS ONE 2: e515.

55. Cheng CM, Lin YW, Bellin RM, Steward RL Jr, Cheng YR, et al. (2010) Probing localized neural mechanotransduction through surface-modified elastomeric matrices and electrophysiology. Nat Protoc 5: 714-724.

56. Usoskin D, Zilberter M, Linnarsson S, Hjerling-Leffler J, Uhlen P, et al. (2010) En masse in vitro functional profiling of the axonal mechanosensitivity of sensory neurons. Proc Natl Acad Sci U S A 107: 16336-16341.

57. Gee KR, Brown KA, Chen WN, Bishop-Stewart J, Gray D, et al. (2000) Chemical and physiological characterization of fluo-4 $\mathrm{Ca}(2+)$-indicator dyes. Cell Calcium 27: 97-106.

58. Paredes RM, Etzler JC, Watts LT, Zheng W, Lechleiter JD (2008) Chemical calcium indicators. Methods 46: 143-151.

59. Fitzgerald EM, Okuse K, Wood JN, Dolphin AC, Moss SJ (1999) cAMPdependent phosphorylation of the tetrodotoxin-resistant voltage-dependent sodium channel SNS. J Physiol 516 ( Pt 2): 433-446.

60. Chalfie M (2009) Neurosensory mechanotransduction. Nat Rev Mol Cell Biol 10: $44-52$.

61. Drew LJ (2009) How do we feel? EMBO J 28: 1378-1379.

62. Sivilotti L, Okuse K, Akopian AN, Moss S, Wood JN (1997) A single serine residue confers tetrodotoxin insensitivity on the rat sensory-neuron-specific sodium channel SNS. FEBS Lett 409: 49-52.

63. Fang X, Djouhri L, Black JA, Dib-Hajj SD, Waxman SG, et al. (2002) The presence and role of the tetrodotoxin-resistant sodium channel $\mathrm{Na}(\mathrm{v}) 1.9(\mathrm{NaN})$ in nociceptive primary afferent neurons. J Neurosci 22: 7425-7433.

64. Lai HC, Jan LY (2006) The distribution and targeting of neuronal voltage-gated ion channels. Nat Rev Neurosci 7: 548-562. 
65. Waxman SG (2006) Axonal conduction and injury in multiple sclerosis: the role of sodium channels. Nat Rev Neurosci 7: 932-941.

66. Meiri H, Pri-Chen S, Korczyn AD (1985) Sodium channel localization in rat sciatic nerve following lead-induced demyelination. Brain Res 359: 326-331.

67. England JD, Gamboni F, Levinson SR, Finger TE (1990) Changed distribution of sodium channels along demyelinated axons. Proc Natl Acad Sci U S A 87: 6777-6780.

68. Smith KJ, Bostock H, Hall SM (1982) Saltatory conduction precedes remyelination in axons demyelinated with lysophosphatidyl choline. J Neurol Sci 54: 13-31.

69. Poliak S, Peles E (2003) The local differentiation of myelinated axons at nodes of Ranvier. Nat Rev Neurosci 4: 968-980.

70. Kole MH, Ilschner SU, Kampa BM, Williams SR, Ruben PC, et al. (2008) Action potential generation requires a high sodium channel density in the axon initial segment. Nat Neurosci 11: 178-186.

71. Engel D, Jonas P (2005) Presynaptic action potential amplification by voltagegated Na+ channels in hippocampal mossy fiber boutons. Neuron 45: 405-417.

72. Oliferenko S, Paiha K, Harder T, Gerke V, Schwarzler C, et al. (1999) Analysis of CD44-containing lipid rafts: Recruitment of annexin II and stabilization by the actin cytoskeleton. J Cell Biol 146: 843-854.

73. Rescher U, Gerke V (2004) Annexins-unique membrane binding proteins with diverse functions. J Cell Sci 117: 2631-2639.

74. Rescher U, Gerke V (2008) S100A10/p11: family, friends and functions. Pflugers Arch 455: 575-582.

75. Shao D, Baker MD, Abrahamsen B, Rugiero F, Malik-Hall M, et al. (2009) A multi PDZ-domain protein Pdzd2 contributes to functional expression of sensory neuron-specific sodium channel $\mathrm{Na}(\mathrm{V}) 1$.8. Mol Cell Neurosci 42: 219-225.

76. Brackenbury WJ, Davis TH, Chen C, Slat EA, Detrow MJ, et al. (2008) Voltagegated $\mathrm{Na}+$ channel betal subunit-mediated neurite outgrowth requires $\mathrm{Fyn}$ kinase and contributes to postnatal CNS development in vivo. J Neurosci 28: 3246-3256.

77. Dart G (2010) Lipid microdomains and the regulation of ion channel function. J Physiol 588: 3169-3178.

78. Hartmann AM, Blaesse P, Kranz T, Wenz M, Schindler J, et al. (2009) Opposite effect of membrane raft perturbation on transport activity of KCC2 and NKCG1. J Neurochem 111: 321-331.

79. Oldfield S, Hancock J, Mason A, Hobson SA, Wynick D, et al. (2009) Receptormediated suppression of potassium currents requires colocalization within lipid rafts. Mol Pharmacol 76: 1279-1289.
80. Cusdin FS, Clare JJ, Jackson AP (2008) Trafficking and cellular distribution of voltage-gated sodium channels. Traffic 9: 17-26.

81. Tillman TS, Cascio M (2003) Effects of membrane lipids on ion channel structure and function. Cell Biochem Biophys 38: 161-190.

82. Phillips R, Ursell T, Wiggins P, Sens P (2009) Emerging roles for lipids in shaping membrane-protein function. Nature 459: 379-385.

83. Lundbaek JA, Birn P, Hansen AJ, Sogaard R, Nielsen C, et al. (2004) Regulation of sodium channel function by bilayer elasticity: the importance of hydrophobic coupling. Effects of Micelle-forming amphiphiles and cholesterol. J Gen Physiol 123: 599-621.

84. Lee AG (2004) How lipids affect the activities of integral membrane proteins. Biochim Biophys Acta 1666: 62-87.

85. Andersen OS, Koeppe RE, 2nd (2007) Bilayer thickness and membrane protein function: an energetic perspective. Annu Rev Biophys Biomol Struct 36: 107130.

86. Wang JA, Lin W, Morris T, Banderali U, Juranka PF, et al. (2009) Membrane trauma and Na+ leak from Nav1.6 channels. Am J Physiol Cell Physiol 297: C823-834.

87. Brown RE (1998) Sphingolipid organization in biomembranes: what physical studies of model membranes reveal. J Cell Sci 111 (Pt 1): 1-9.

88. Simons K, Toomre D (2000) Lipid rafts and signal transduction. Nat Rev Mol Cell Biol 1: 31-39.

89. Tsui-Pierchala BA, Encinas M, Milbrandt J, Johnson EM Jr (2002) Lipid rafts in neuronal signaling and function. Trends Neurosci 25: 412-417.

90. Okuse K (2007) Pain signalling pathways: from cytokines to ion channels. Int J Biochem Cell Biol 39: 490-496.

91. Botto L, Masserini M, Palestini P (2007) Changes in the composition of detergent-resistant membrane domains of cultured neurons following protein kinase C activation. J Neurosci Res 85: 443-450.

92. Limpert AS, Karlo JC, Landreth GE (2007) Nerve growth factor stimulates the concentration of TrkA within lipid rafts and extracellular signal-regulated kinase activation through c-Cbl-associated protein. Mol Cell Biol 27: 5686-5698.

93. Cummins TR, Howe JR, Waxman SG (1998) Slow closed-state inactivation: a novel mechanism underlying ramp currents in cells expressing the hNE/PN1 sodium channel. J Neurosci 18: 9607-9619.

94. Rush AM, Dib-Hajj SD, Liu S, Cummins TR, Black JA, et al. (2006) A single sodium channel mutation produces hyper- or hypoexcitability in different types of neurons. Proc Natl Acad Sci U S A 103: 8245-8250. 